\title{
Towards operando Characterisation by Powder Diffraction Techniques of Molecular Sieves
}

\author{
C. Pichon ${ }^{1}$, H. Palancher ${ }^{1}, 2$, J.L. Hodeau ${ }^{2}$ and J.F. Bérar ${ }^{2,3}$ \\ 1 IFP- Lyon, BP 3, 69390 Vernaison - France \\ 2 Laboratoire de Cristallographie (CNRS), BP 166, 25, avenue des Martyrs, 38042 Grenoble Cedex - France \\ 3 D2AM- CRG française (ESRF), BP 220, 6, rue Jules Horowitz, 38043 Grenoble Cedex - France \\ e-mail: christophe.pichon@ifp.fr - herve.palancher@esrf.fr - hodeau@grenoble.cnrs.fr - berar@esrf.fr
}

\begin{abstract}
Résumé - Vers la caractérisation operando de tamis moléculaires par diffraction par les poudres - Les tamis moléculaires en poudres présentent des atomes nombreux et variés. Leur caractérisation nécessite des sondes sélectives chimiquement. Ils peuvent être caractérisés soit par diffraction des neutrons soit par diffraction anomale des rayons $\mathrm{X}$ pour obtenir des informations sur la structure de ces matériaux. Nous allons illustrer la complémentarité de ces méthodes par l'analyse de deux processus chimiques sur des zéolithes X.

Dans une première partie, nous présentons l'analyse structurale d'une zéolithe $\mathrm{X}$ échangée au baryum par diffraction des neutrons après une étape de préparation ex situ consistant à saturer la zéolithe $\mathrm{BaX}$ par un mélange d'eau lourde et de para-xylène deutéré. La sensibilité aux atomes légers de la diffraction des neutrons nous a permis de proposer une localisation précise des molécules d'eau et de xylène composant la phase adsorbée dans la micro-porosité de la zéolithe.

La deuxième partie de ce travail est dédiée à la caractérisation structurale pendant le processus de déshydratation de la zéolithe $\mathrm{X}$ échangée par les cations strontium et rubidium. Cette caractérisation in situ a été obtenue par l'enregistrement, pour chaque état de la zéolithe (hydratée, déshydratée), de trois diagrammes de diffraction des rayons $\mathrm{X}$, deux à une énergie proche du seuil d'absorption des rayons $\mathrm{X}$ de chaque cation de compensation $\left(\mathrm{Sr}^{2+}\right.$ et $\left.\mathrm{Rb}^{+}\right)$et un loin de ces deux seuils d'absorption. La sélectivité chimique de la diffraction résonante a permis d'obtenir des informations précises sur la distribution des cations de compensation (en termes de localisation et de répartition) et sur leur mobilité en fonction des conditions expérimentales.
\end{abstract}

En conclusion, nous résumons quelques spécificités et limitations des deux méthodes.

\begin{abstract}
Towards operando Characterisation by Powder Diffraction Techniques of Molecular Sieves-Working molecular sieves imply numerous and various atoms and for their characterisation we need chemical selective probes. Thus they can be studied either by neutron powder diffraction or by anomalous X-ray powder diffraction techniques to extract structural information. We will illustrate the complementarities of these methods in the analysis of two different chemical processes on X-type zeolite.
\end{abstract}

In the first case, a fully exchanged barium X-type zeolite was, firstly, characterised by neutron powder diffraction after an ex situ preparation step. During the preparation step, the sample was saturated with 
a mixture of heavy water and deuterated para-xylene. The selectivity of neutron diffraction for light elements allows the precise location of both water and xylene molecules.

In the second example, an X-type zeolite exchanged by both strontium and rubidium cations was studied during the dehydration process. The in situ structural characterisation was performed by recording, for each state of the zeolite (hydrated, dehydrated), three X-ray powder patterns. Two of them were measured at an energy close to the absorption edge of each compensating cation $\left(\mathrm{Sr}^{2+}\right.$ and $\left.\mathrm{Rb}^{+}\right)$and one far from both absorption edges. The chemical selectivity of resonant diffraction allows an accurate determination of the distribution of compensating cations (location, distribution and mobility) during the dehydration process.

Finally a comparison of some specificities and limitations of both methods are summarized.

\section{INTRODUCTION}

High performance industrial processes for separation and purification of hydrocarbons isomers are based on selective adsorption properties of molecular sieves such as X, Y and A zeolites exchanged with various cations. In particular, X-type zeolites are currently used in industrial separation processes of para-xylene from the other $\mathrm{C}_{8}$ aromatic isomers [1].

The X-type zeolite is an alumino-silicate which belongs to the Faujasite family (structure type FAU [2]). X zeolites are characterised by a Si/Al ratio in the range 1.0-1.5. The framework structure has cubic symmetry and it is built of sodalite cages (also called $\beta$-cages) linked together by hexagonal prisms. The large cavity created by the periodical arrangement of the sodalite cages is called the supercage. Each supercage is connected to four sodalite cages through a 6-ring window (with a free aperture diameter of $0.22 \mathrm{~nm}$ ) and to four other supercages through a 12-ring window (with a free aperture diameter of $0.75 \mathrm{~nm}$ ). The structure of the $\mathrm{X}$ zeolite is presented in Figure 1.

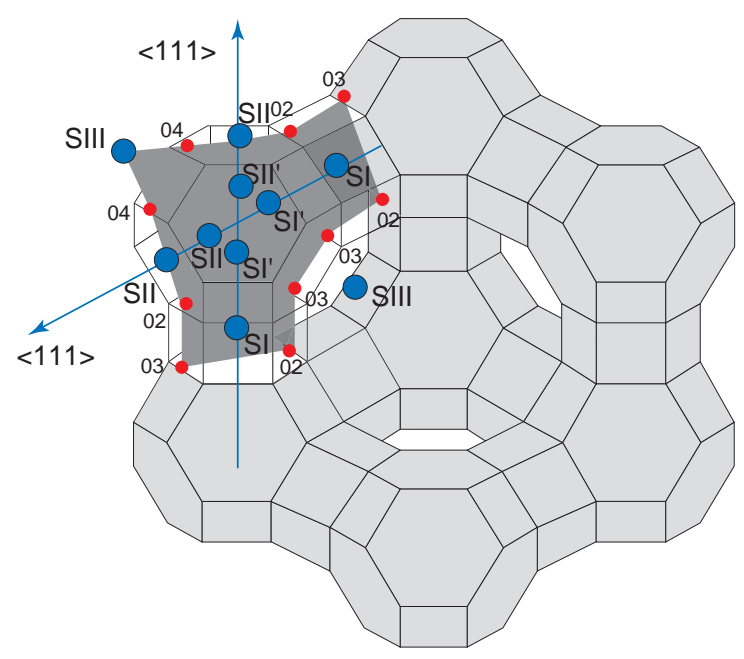

Figure 1

Structure and cationic sites of the Faujasite zeolite.
Because of the presence of $\mathrm{AlO}_{4}$ tetrahedra, the framework of the zeolite is globally negatively charged. The electrical neutrality of the material is assured by charge compensating cations. In X-type zeolite, four main crystallographic sites, located in all cavities, can be occupied by cations [3] (Fig. 1). The occupancy factor of each cationic site can be influenced by various parameters and, in particular, by the composition and the amount of the adsorbed phase, the nature and the charge of the compensating cation and the presence of a second type of cation (bicationic zeolites). Since the cationic distribution seems to be a key parameter in the understanding of selective adsorption properties of zeolite, it is of great interest to be able to determine the cationic distribution of the zeolite under working conditions of the process. Thus, to improve our understanding of selective adsorption phenomena, the precise location of adsorbed molecules is an essential structural information.

For X-rays, the intensity diffracted by an element is proportional to the square of its number of electrons. As a consequence, X-ray powder diffraction is a technique wellsuited to perform structural characterisation of dehydrated $\mathrm{X}$ zeolites since the framework is highly crystallised and the cationic element is often heavy. However, the location of lighter elements (typically carbon and hydrogen) in a heavier matrix ( $\mathrm{Si}, \mathrm{Al}, \mathrm{O})$ is not easy using classical $\mathrm{X}$-ray diffraction. For the same reason, the discrimination between elements with close atomic number can be difficult.

Thus we need to improve diffraction methods and there are two ways to enhance or to change the contrast obtained by classical X-ray diffraction between two given elements:

- The first one is obtained by neutron diffraction, since for neutrons the nuclear scattering length, which depends on the isotope and nuclear spin state, is not related to the atomic number.

- The second method uses resonant diffraction, also called anomalous diffraction: around adsorption edge energies of an element, atomic scattering factor variations range from 5 to 20 electron units (e.u.) per atom, thus providing an additional contrast [4-6].

$\mathrm{X}$-ray resonant (or anomalous) diffraction specificity is related to the close relationship between scattering, 
absorption and refraction. Resonant scattering refers to the modification of its intensity due to absorption processes involving interactions between the X-ray beam and the atoms in the sample. This interaction combines the chemical and short-range order sensitivity of absorption with the longrange order sensitivity of diffraction. However this method is relatively complex as it is necessary to collect accurate diffraction diagrams close to absorption edges. But in spite of this complexity and due to its chemical selectivity, resonant diffraction has found many applications ranging from pure crystallographic methods like structure factor phase determination by Multi-wavelength Anomalous Diffraction (MAD) to pure spectroscopic ones like Diffraction Anomalous Fine Structure (DAFS) [4].

Neutron scattering lengths are not a smooth function of atomic number, thus neutron diffraction can be a useful tool to discriminate neighbouring atomic number elements. Furthermore, the constant value of neutron scattering lengths versus $\sin \theta / \lambda$ allows an easier separation of occupancy contribution from atomic displacements contribution. Due to absorption edges energies, resonant scattering technique can only be used for elements with an atomic number higher than $20 \mathrm{X}$-ray resonant diffraction does not enable an accurate location of hydrocarbon molecules adsorbed in zeolites. On the contrary, using neutron diffraction, carbon and deuterium (hydrogen, with its incoherent scattering, is not an easy to handle nucleus) atoms have high nuclear scattering lengths in spite of their low atomic number and they contribute strongly to the neutron diffraction pattern. The efficiency of neutron diffraction to locate aromatic molecules (benzene) in the $\mathrm{NaY}$ zeolite channels has been demonstrated [7].

We can also combine X-ray and neutron powder diffraction to investigate materials. Using these two methods, the crystallographic structure of dehydrated $\mathrm{CaX}$ zeolite was solved, taking advantage of the higher sensitivity of X-rays for the cation while improved accuracy in framework structure is given by the neutron study [8].

The structural characterisation under working conditions of these molecular sieves implies their study under temperature and under dynamic hydrocarbon molecule adsorption conditions. This article will first deal with the challenges for the implementation of such reactors on neutron and X-ray diffractometers and with the interest of such a strategy when taking into account the specificities of each diffraction technique (sample size and absorption, sample environment, elements and scattering factors/lengths, etc.).

Moreover, the efficiency of neutron and resonant X-ray powder diffraction will be illustrated by two examples, one dedicated to the structural characterisation by neutron diffraction of a zeolite $\mathrm{BaX}$ saturated by a mixture of water and para-xylene and the second where a bicationic zeolite $\mathrm{SrRbX}$ was studied by anomalous $\mathrm{X}$-ray diffraction during the dehydration process.

\section{STRUCTURAL CHARACTERISATION OF A SATURATED ZEOLITE BAX BY NEUTRON POWDER DIFFRACTION}

\subsection{Aim of the Study}

The petrochemical industry of BTX (benzene, toluene and xylenes) has experienced important economic development as a result of a constant increase of the use of para-xylene. Para-xylene is the starting material for the synthesis of an essential polyester: polyethylene terephthalate (PET). The separation of para-xylene from the $\mathrm{C}_{8}$ aromatic cut can be performed by selective adsorption of this isomer on zeolite $\mathrm{BaX}$ where the selectivity in favour with the para-xylene appears when the molecular sieve contains a small amount of water (about 5\% in weight) and is saturated with xylene [9].

For a better understanding of the selective adsorption of para-xylene on this adsorbing material, we have performed a neutron powder diffraction study of partially hydrated zeolite $\mathrm{BaX}$ that provides further insight at a molecular level for the adsorption of para-xylene in zeolite $\mathrm{BaX}$.

\subsection{Experimental Section}

\subsubsection{Sample Preparation and Characterisation}

The zeolite $\mathrm{BaX}$ (unit cell composition determined by atomic absorption and X-ray fluorescence: $\mathrm{Na}_{3} \mathrm{Ba}_{43} \mathrm{Si}_{109} \mathrm{Al}_{84} \mathrm{O}_{384}$ ) was obtained by ion exchange of a synthetic zeolite $\mathrm{NaX}$ $\left(\mathrm{Na}_{83} \mathrm{Si}_{108} \mathrm{Al}_{85} \mathrm{O}_{384}\right)$ supplied by Carlo Erba. The ion exchange was performed on a micrometrical powder in aqueous solution using typical conditions [9].

The obtained zeolite powder was then placed into a glass cell. The cell was connected to vacuum and adsorption branches to allow dehydration and adsorption of heavy water or pure deuterated para-xylene (supplied by Eurisotop, which warrants an isotopic enrichment in excess of 98\%). The dehydration of the sample was performed under vacuum $\left(10^{-4} \mathrm{~Pa}\right)$ at $623 \mathrm{~K}$ for $24 \mathrm{~h}$. The glass cell was then isolated from the pumping system to begin the adsorption step. The adsorption of heavy water was done first at $473 \mathrm{~K}$. It is emphasised that the water content was controlled very accurately. The adsorption step was then completed, at $423 \mathrm{~K}$, by admitting pure deuterated para-xylene vapour at a controlled pressure. The sample was prepared in order to be loaded with 5\% in weight of heavy water and $17 \%$ in weight of deuterated para-xylene. The amount of adsorbed water and para-xylene was determined by weighing the samples before and after the adsorption. Table 1 summarises the molar content of the adsorbed phase. The cell was then transferred to a nitrogen-conditioned glove-box where the zeolite sample (about $6 \mathrm{~g}$ of powder) was placed in air-tight vanadium cylindrical sample holders $(1.5 \mathrm{~cm}$ diameter and $6 \mathrm{~cm}$ height $)$. The sample holders were made air-tight with an indium seal. 
TABLE 1

Experimental and crystallographic data for neutron powder diffraction study of zeolite $\mathrm{BaX}$ partially hydrated and saturated with para-xylene

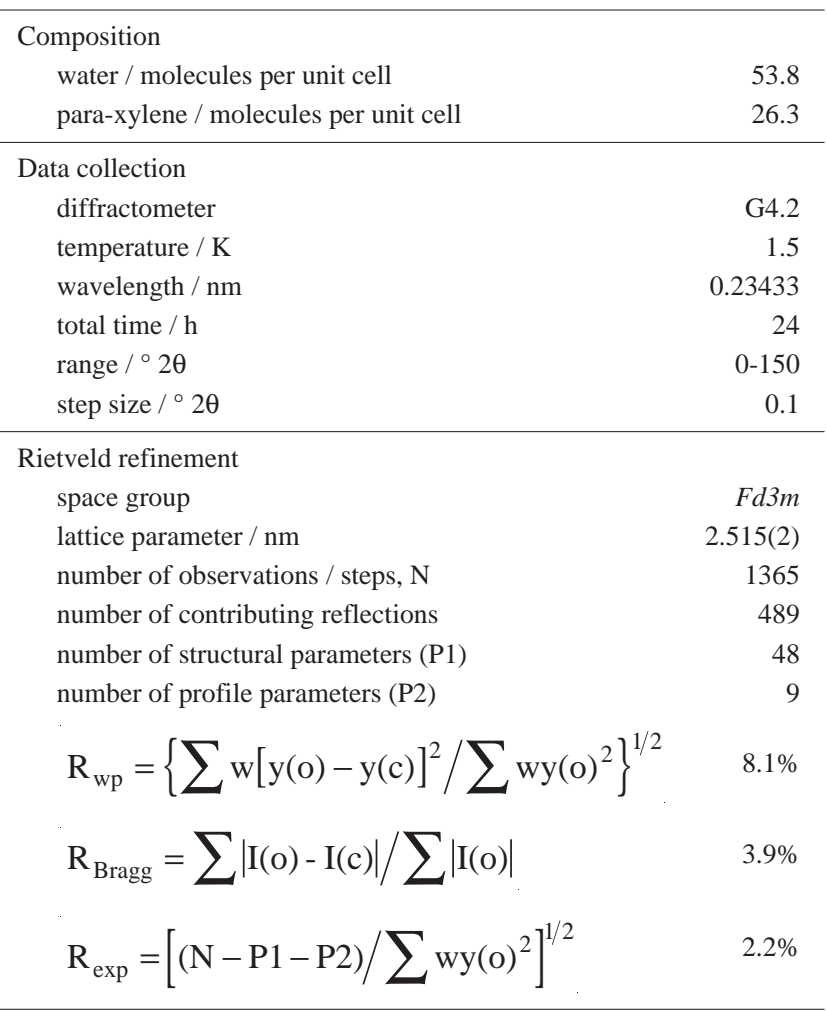

\subsubsection{Data Collection and Structure Refinement}

The powder pattern of the sample was recorded at low temperature on the G4.2 diffractometer at the Laboratoire Léon Brillouin CEA-CNRS (Saclay, France). The experimental counting statistics were good enough to perform the Rietveld refinement of the structure. The experimental conditions of the recording of the data are specified in Table 1. The diffraction patterns were analysed by the Rietveld refinement method [10] using the GSAS software package [11]. The space group used was Fd3m, since there was no indication in the powder pattern of a lower symmetry (e.g. additional lines, peak splitting, etc.) that may have been induced by the adsorption of the para-xylene molecules. Firstly, the profile parameters, the background parameters, the unit cell constant and the zero-point were optimised. After a preliminary refinement of the framework geometry, the adsorbed para-xylene and water molecules were located with a series of difference Fourier maps. The para-xylene molecules were refined as rigid bodies. All restraints on the framework atoms and on population parameters of the host molecules were progressively released during the refinement. The Rietveld plot for the refinement is shown in Figure 2 and Rietveld refinement parameters are reported in Table 1. The refined structural parameters obtained for zeolite $\mathrm{BaX}$

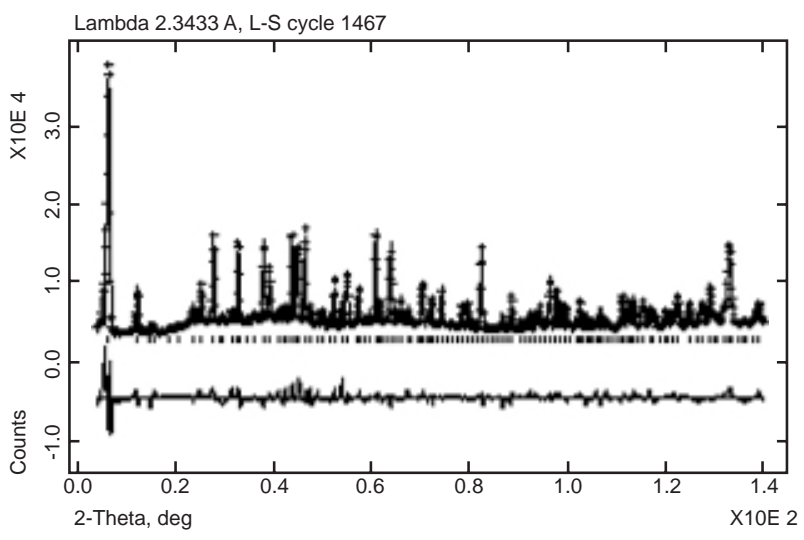

Figure 2

Neutron powder pattern and Rietveld plot for the refinement of zeolite BaX partially hydrated and saturated with para-xylene. Upper part: + experimental data; - calculated profile. Lower part: - difference between experimental and calculated profiles.

partially hydrated and saturated with para-xylene are reported in Table 2.

\subsection{Results}

\subsubsection{Structure of the Framework and Location of Barium Cations}

After Rietveld refinement of the data, the structure of the framework obtained is comparable with data previously reported in the literature $[12,13]$ and no strong deformation of the crystal structure was noticed. The average ( $\mathrm{Si}, \mathrm{Al})-\mathrm{O}$ distance of $0.166(8) \mathrm{nm}$ is in good agreement with values expected for the $\mathrm{Si} / \mathrm{Al}$ ratio of 1.3. Barium cations appeared to be located essentially in the supercage: when partially hydrated zeolite $\mathrm{BaX}$ is saturated with para-xylene, site SII is full. Small amounts of barium cations were also found at site SI' (in the sodalite cage) and at site SI (at the centre of the hexagonal prism). Some characteristic distances between the cations and framework oxygens are given in Table 3. The occupancy factor of each site calculated in terms of numbers of cations per cage (supercage or sodalite cage) is reported in Table 4.

\subsubsection{Location of Water Molecules}

After a partial Rietveld refinement, subsequent difference Fourier calculations allowed finding out two different adsorption sites for water molecules, w1 and w2. The site w1 is coordinated to the $\mathrm{Ba}^{2+}$ cation in site SI' (Fig. 3). It forms hydrogen bridges to the framework oxygens, indicated by $\mathrm{O}_{\text {water }}-\mathrm{O}_{\text {framework }}$ distances of $0.275(1) \mathrm{nm}$. The other adsorption site, w2, is in the supercage close to the $\mathrm{Ba}^{2+}$ cation in site SII (Fig. 4). In this position, a strong interaction is also observed between the water molecule and the framework 
TABLE 2

Fractional coordinates, isotropic displacement factors $\mathrm{U}$, and population parameters PP for $\mathrm{BaX}$ zeolite partially hydrated and saturated with para-xylene

\begin{tabular}{|c|c|c|c|c|c|c|}
\hline Atom & Position multiplicity & $\mathrm{x}$ & $\mathrm{y}$ & $\mathrm{z}$ & $\mathrm{U}(\times 100)$ & PP \\
\hline $\mathrm{SiAl}$ & 192 & $-0.0562(4)$ & $0.0367(6)$ & $0.1265(3)$ & $1.3(3)^{\mathrm{a}}$ & 1 \\
\hline $\mathrm{O}(1)$ & 96 & $-0.1054(2)$ & 0 & $0.1054(2)$ & $1.3(3)^{\mathrm{a}}$ & 1 \\
\hline $\mathrm{O}(2)$ & 96 & 0 & 0 & $0.1378(3)$ & $1.3(3)^{\mathrm{a}}$ & 1 \\
\hline $\mathrm{O}(3)$ & 96 & $-0.0402(3)$ & $0.0799(3)$ & $0.0799(3)$ & $1.3(3)^{\mathrm{a}}$ & 1 \\
\hline $\mathrm{O}(4)$ & 96 & $-0.0696(5)$ & $0.0656(4)$ & $0.1843(2)$ & $1.3(3)^{\mathrm{a}}$ & 1 \\
\hline $\mathrm{Ba}(1)$ & 16 & 0 & 0 & 0 & $4.7(3)$ & $0.169(2)$ \\
\hline $\mathrm{Ba}\left(1^{\prime}\right)$ & 32 & $0.0668(3)$ & $0.0668(3)$ & $0.0668(3)$ & $9.5(1)$ & $0.269(2)$ \\
\hline $\mathrm{Ba}(2)$ & 32 & $0.2475(2)$ & $0.2475(2)$ & $0.2475(2)$ & $3.7(3)$ & $1.00(1)$ \\
\hline $\mathrm{Na}\left(1^{\prime}\right)$ & 32 & $0.0405(4)$ & $0.0405(4)$ & $0.0405(4)$ & $4.5(2)$ & $0.047(3)$ \\
\hline $\mathrm{O}(\mathrm{w} 1)$ & 32 & $0.1780(3)$ & $0.1780(3)$ & $0.1780(3)$ & $10.1(2)^{b}$ & $0.378(4)^{\mathrm{f}}$ \\
\hline D1(w1) & 96 & $0.1588(2)$ & $0.1588(2)$ & $0.1513(2)$ & $10.1(2)^{b}$ & $0.126(1)^{f}$ \\
\hline D2(w1) & 96 & $0.2011(4)$ & $0.2011(4)$ & $0.1583(3)$ & $10.1(2)^{b}$ & $0.126(1)^{\mathrm{f}}$ \\
\hline $\mathrm{O}(\mathrm{w} 2)$ & 96 & $0.3172(2)$ & $0.1940(4)$ & $0.3172(2)$ & $6.2(3)^{\mathrm{c}}$ & $0.434(2)^{\mathrm{g}}$ \\
\hline D1(w2) & 96 & $0.3035(2)$ & $0.1612(3)$ & $0.3035(2)$ & $6.2(3)^{\mathrm{c}}$ & $0.434(2)^{\mathrm{g}}$ \\
\hline D2(w2) & 96 & $0.2979(3)$ & $0.2207(4)$ & $0.2979(3)$ & $6.2(3)^{\mathrm{c}}$ & $0.434(2)^{\mathrm{g}}$ \\
\hline $\mathrm{C} 1(\mathrm{p} 1)$ & 192 & $0.3195(2)$ & $0.3122(3)$ & $0.3088(3)$ & $9.5(4)^{d}$ & $0.096(2)^{\mathrm{h}}$ \\
\hline $\mathrm{C} 2(\mathrm{p} 1)$ & 192 & $0.2958(5)$ & $0.2840(3)$ & $0.3497(4)$ & $9.5(4)^{d}$ & $0.096(2)^{\mathrm{h}}$ \\
\hline $\mathrm{C} 3(\mathrm{p} 1)$ & 192 & $0.2450(3)$ & $0.2973(3)$ & $0.3663(2)$ & $9.5(4)^{d}$ & $0.096(2)^{\mathrm{h}}$ \\
\hline $\mathrm{C} 4(\mathrm{p} 1)$ & 192 & $0.2180(4)$ & $0.3387(4)$ & $0.3421(5)$ & $9.5(4)^{\mathrm{d}}$ & $0.096(2)^{\mathrm{h}}$ \\
\hline $\mathrm{C} 5(\mathrm{p} 1)$ & 192 & $0.2418(3)$ & $0.3668(4)$ & $0.3012(4)$ & $9.5(4)^{\mathrm{d}}$ & $0.096(2)^{\mathrm{h}}$ \\
\hline C6(p1) & 192 & $0.2926(4)$ & $0.3536(5)$ & $0.2846(3)$ & $9.5(4)^{d}$ & $0.096(2)^{\mathrm{h}}$ \\
\hline $\mathrm{C} 7(\mathrm{p} 1)$ & 192 & $0.3748(6)$ & $0.2977(3)$ & $0.2907(3)$ & $9.5(4)^{d}$ & $0.096(2)^{\mathrm{h}}$ \\
\hline $\mathrm{C} 8(\mathrm{p} 1)$ & 192 & $0.1627(5)$ & $0.3531(4)$ & $0.3602(2)$ & $9.5(4)^{d}$ & $0.096(2)^{\mathrm{h}}$ \\
\hline $\mathrm{D} 1(\mathrm{p} 1)$ & 192 & $0.3169(3)$ & $0.2516(3)$ & $0.3686(2)$ & $9.5(4)^{\mathrm{d}}$ & $0.096(2)^{\mathrm{h}}$ \\
\hline $\mathrm{D} 2(\mathrm{p} 1)$ & 192 & $0.2264(4)$ & $0.2752(3)$ & $0.3983(3)$ & $9.5(4)^{\mathrm{d}}$ & $0.096(2)^{\mathrm{h}}$ \\
\hline $\mathrm{D} 3(\mathrm{p} 1)$ & 192 & $0.2207(4)$ & $0.3992(2)$ & $0.2822(5)$ & $9.5(4)^{d}$ & $0.096(2)^{\mathrm{h}}$ \\
\hline D4(p1) & 192 & $0.3112(3)$ & $0.3756(3)$ & $0.2526(4)$ & $9.5(4)^{d}$ & $0.096(2)^{\mathrm{h}}$ \\
\hline D5(p1) & 192 & $0.4039(2)$ & $0.3193(2)$ & $0.3123(4)$ & $9.5(4)^{d}$ & $0.096(2)^{\mathrm{h}}$ \\
\hline D6(p1) & 192 & $0.3823(3)$ & $0.2567(5)$ & $0.2963(5)$ & $9.5(4)^{\mathrm{d}}$ & $0.096(2)^{\mathrm{h}}$ \\
\hline D7(p1) & 192 & $0.3801(2)$ & $0.3064(3)$ & $0.2498(4)$ & $9.5(4)^{\mathrm{d}}$ & $0.096(2)^{\mathrm{h}}$ \\
\hline $\mathrm{D} 8(\mathrm{p} 1)$ & 192 & $0.1336(5)$ & $0.3315(3)$ & $0.3386(3)$ & $9.5(4)^{\mathrm{d}}$ & $0.096(2)^{\mathrm{h}}$ \\
\hline D9(p1) & 192 & $0.1575(5)$ & $0.3445(3)$ & $0.4011(2)$ & $9.5(4)^{d}$ & $0.096(2)^{\mathrm{h}}$ \\
\hline $\mathrm{D} 10(\mathrm{p} 1)$ & 192 & $0.1552(4)$ & $0.3942(3)$ & $0.3546(3)$ & $9.5(4)^{d}$ & $0.096(2)^{\mathrm{h}}$ \\
\hline $\mathrm{C} 1(\mathrm{p} 2)$ & 192 & $0.5506(3)$ & $0.5003(3)$ & $0.4783(2)$ & $6.8(2)^{\mathrm{e}}$ & $0.041(3)^{i}$ \\
\hline $\mathrm{C} 2(\mathrm{p} 2)$ & 192 & $0.5426(3)$ & $0.4807(4)$ & $0.5290(3)$ & $6.8(2)^{\mathrm{e}}$ & $0.041(3)^{\mathrm{i}}$ \\
\hline $\mathrm{C} 3(\mathrm{p} 2)$ & 192 & $0.4920(4)$ & $0.4804(5)$ & $0.5508(2)$ & $6.8(2)^{\mathrm{e}}$ & $0.041(3)^{\mathrm{i}}$ \\
\hline $\mathrm{C} 4(\mathrm{p} 2)$ & 192 & $0.4494(3)$ & $0.4997(2)$ & $0.5218(2)$ & $6.8(2)^{\mathrm{e}}$ & $0.041(3)^{\mathrm{i}}$ \\
\hline $\mathrm{C} 5(\mathrm{p} 2)$ & 192 & $0.4574(4)$ & $0.5193(5)$ & $0.4710(3)$ & $6.8(2)^{\mathrm{e}}$ & $0.041(3)^{\mathrm{i}}$ \\
\hline C6(p2) & 192 & $0.5080(3)$ & $0.5196(2)$ & $0.4492(4)$ & $6.8(2)^{\mathrm{e}}$ & $0.041(3)^{\mathrm{i}}$ \\
\hline $\mathrm{C} 7(\mathrm{p} 2)$ & 192 & $0.5889(5)$ & $0.4597(5)$ & $0.5607(6)$ & $6.8(2)^{\mathrm{e}}$ & $0.041(3)^{\mathrm{i}}$ \\
\hline $\mathrm{C} 8(\mathrm{p} 2)$ & 192 & $0.4111(4)$ & $0.5404(3)$ & $0.4393(4)$ & $6.8(2)^{\mathrm{e}}$ & $0.041(3)^{\mathrm{i}}$ \\
\hline D1(p2) & 192 & $0.5901(2)$ & $0.5006(2)$ & $0.4612(3)$ & $6.8(2)^{\mathrm{e}}$ & $0.041(3)^{\mathrm{i}}$ \\
\hline $\mathrm{D} 2(\mathrm{p} 2)$ & 192 & $0.4858(4)$ & $0.4650(5)$ & $0.5906(3)$ & $6.8(2)^{\mathrm{e}}$ & $0.041(3)^{\mathrm{i}}$ \\
\hline D3(p2) & 192 & $0.4099(5)$ & $0.4994(5)$ & $0.5388(4)$ & $6.8(2)^{\mathrm{e}}$ & $0.041(3)^{\mathrm{i}}$ \\
\hline D4(p2) & 192 & $0.5142(3)$ & $0.5350(2)$ & $0.4095(3)$ & $6.8(2)^{\mathrm{e}}$ & $0.041(3)^{\mathrm{i}}$ \\
\hline D5(p2) & 192 & $0.5983(2)$ & $0.4151(4)$ & $0.5559(2)$ & $6.8(2)^{\mathrm{e}}$ & $0.041(3)^{\mathrm{i}}$ \\
\hline D6(p2) & 192 & $0.5862(3)$ & $0.4638(5)$ & $0.6060(2)$ & $6.8(2)^{\mathrm{e}}$ & $0.041(3)^{\mathrm{i}}$ \\
\hline D7(p2) & 192 & $0.6291(3)$ & $0.4786(6)$ & $0.5522(5)$ & $6.8(2)^{\mathrm{e}}$ & $0.041(3)^{\mathrm{i}}$ \\
\hline D8(p2) & 192 & $0.4018(4)$ & $0.5849(3)$ & $0.4441(4)$ & $6.8(2)^{\mathrm{e}}$ & $0.041(3)^{\mathrm{i}}$ \\
\hline D9(p2) & 192 & $0.4139(4)$ & $0.5362(4)$ & $0.3940(5)$ & $6.8(2)^{\mathrm{e}}$ & $0.041(3)^{\mathrm{i}}$ \\
\hline $\mathrm{D} 10(\mathrm{p} 2)$ & 192 & $0.3704(5)$ & $0.5214(3)$ & $0.4478(4)$ & $6.8(2)^{\mathrm{e}}$ & $0.041(3)^{\mathrm{i}}$ \\
\hline
\end{tabular}

a-i: Parameters with the same superscript were constrained to be equal. 
and we note a $\mathrm{O}_{\text {water }}-\mathrm{O}_{\text {framework }}$ distance of $0.278(3) \mathrm{nm}$ which may be associated with a hydrogen bridge.

\section{TABLE 3}

Selected interatomic distances for framework atoms, water and para-xylene molecules

\begin{tabular}{l|c|c}
\hline Area & Bond & $\begin{array}{c}\text { Interatomic } \\
\text { distances }\end{array}$ \\
\hline supercage & $(\mathrm{Si} . \mathrm{Al})-\mathrm{O}_{\text {frame. }}$ & $0.166(8) \mathrm{nm}$ \\
sodalite cage & $\mathrm{Ba}(2)-\mathrm{O}(2)_{\text {frame. }}$ & $0.276(0) \mathrm{nm}$ \\
sodalite cage & $\mathrm{Ba}\left(1^{\prime}\right)-\mathrm{O}(3)_{\text {frame. }}$ & $0.273(1) \mathrm{nm}$ \\
sodalite cage & $\mathrm{O}_{\text {water }}-\mathrm{Ba}\left(1^{\prime}\right)$ & $0.280(3) \mathrm{nm}$ \\
sodalite cage & $\mathrm{O}_{\text {water }}-\mathrm{O}_{\text {water }}$ & $0.377(1) \mathrm{nm}$ \\
sodalite cage & $\mathrm{O}_{\text {water }}-\mathrm{O}(2)_{\text {frame. }}$ & $0.275(1) \mathrm{nm}$ \\
supercage & $\mathrm{D}_{\text {water }}-\mathrm{O}(2)_{\text {frame. }}$ & $0.181(5) \mathrm{nm}$ \\
supercage & $\mathrm{O}_{\text {water }}-\mathrm{Ba}(2)$ & $0.281(8) \mathrm{nm}$ \\
supercage & $\mathrm{O}_{\text {water }}-\mathrm{O}_{\text {water }}$ & $0.437(9) \mathrm{nm}$ \\
supercage & $\mathrm{O}_{\text {water }}-\mathrm{O}(2)_{\text {frame. }}$ & $0.278(3) \mathrm{nm}$ \\
supercage (cationic site) & $\mathrm{D}_{\text {water }}-\mathrm{O}(2)_{\text {frame. }}$ & $0.199(1) \mathrm{nm}$ \\
supercage (cationic site) & $\mathrm{c}_{\text {aro }}-\mathrm{Ba}(2)^{\mathrm{b}}{ }^{\mathrm{b}}$ & $0.28(2) \mathrm{nm}$ \\
supercage (cationic site) & $\mathrm{C}_{\text {aliph }}-\mathrm{O}_{\text {frame. }}{ }^{\mathrm{c}}$ & $0.297(0) \mathrm{nm}$ \\
supercage (non-cationic site) & $\mathrm{D}_{\text {aliph }}-\mathrm{O}_{\text {frame. }}{ }^{\mathrm{c}}$ & $0.193(8) \mathrm{nm}$ \\
supercage (non-cationic site) & $\mathrm{C}_{\text {aliph }}-\mathrm{O}_{\text {frame. }}{ }^{\mathrm{c}}$ & $0.334(2) \mathrm{nm}$ \\
& $\mathrm{D}_{\text {aliph }}-\mathrm{O}_{\text {frame. }}$ & $0.236(6) \mathrm{nm}$ \\
\hline
\end{tabular}

a: average distance; $b$ : $c_{\text {aro }}=$ center of the aromatic ring; $c$ : $\mathrm{C}_{\text {aliph }}=$ aliphatic carbon of the xylene molecule.

\section{TABLE 4}

Distribution of $\mathrm{Ba}^{2+}$ cations, water and para-xylene molecules per cavity (or per $1 / 8$ of unit cell)

\begin{tabular}{l|c|c}
\hline \multirow{3}{*}{ barium cation } & $\mathrm{Ba}(1)($ site SI) & 0.3 \\
& $\mathrm{Ba}\left(1^{\prime}\right)($ site SI') & 1.1 \\
& $\mathrm{Ba}(2)($ site SII) & 4.0 \\
& total & 5.4 \\
\hline \multirow{3}{*}{ water } & sodalite cage (site w1) & 1.5 \\
& supercage (site w2) & 5.2 \\
& total & 6.7 \\
\hline \multirow{3}{*}{ para-xylene } & cationic site & 2.3 \\
& non-cationic site & 1.0 \\
& total & 3.3 \\
\hline
\end{tabular}

For partially hydrated zeolite $\mathrm{BaX}$ saturated with paraxylene, water molecules were essentially located in the supercage and the ratio between water molecules located in the supercage and water molecules located in the sodalite cage is 3.5 to 1 (Table 4). Selected distances between the water molecules at sites w1 and w2 and other atoms of the unit cell are also reported in Table 3.

\subsubsection{Location of Para-Xylene Molecules}

The para-xylene molecules were found at two different adsorption sites, both located in the supercage, which is the only
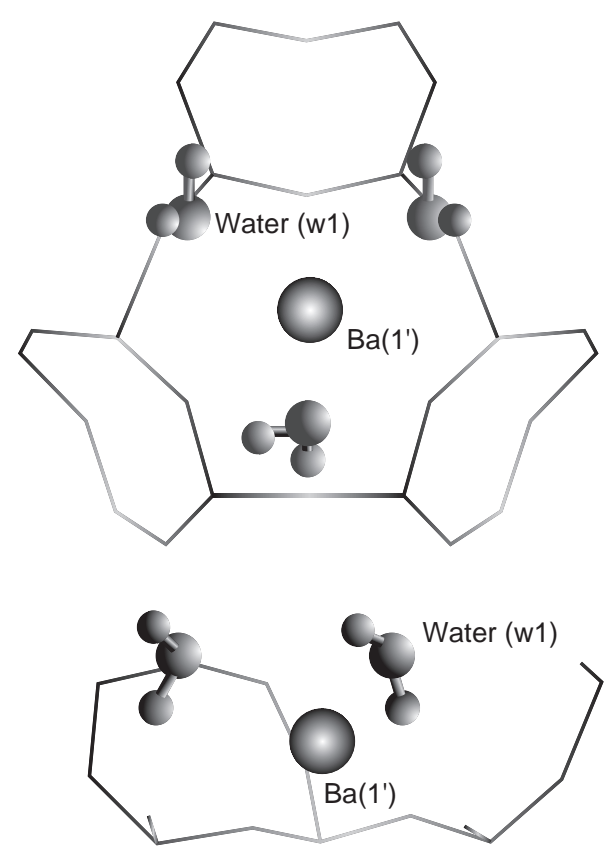

Figure 3

Adsorption site in the sodalite cage for water in the partially hydrated zeolite BaX saturated with para-xylene. (a) Front view of w1; (b) side view of w1.

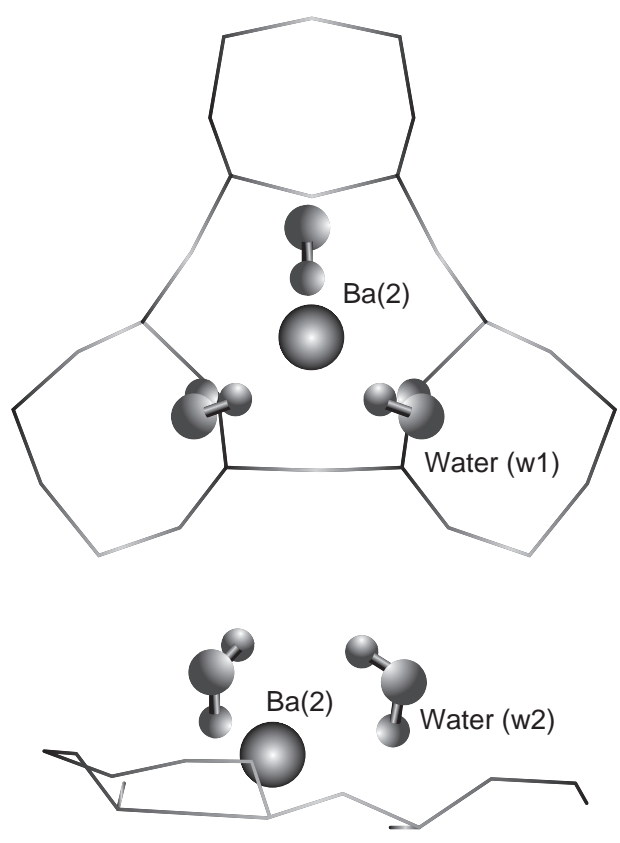

Figure 4

Adsorption site in the supercage for water in the partially hydrated zeolite BaX saturated with para-xylene. (a) Front view of w2; (b) side view of w2. 
cavity of the X-type zeolite accessible for xylene isomers. Under the experimental conditions selected for saturating the molecular sieve, a total of 3.3 para-xylene molecules per supercage were adsorbed in partially hydrated zeolite $\mathrm{BaX}$.

The preferential adsorption site is located close to a $\mathrm{Ba}(2)$. The centre of the aromatic ring is on a mirror plane but off the 3-fold axis of the supercage (Fig. 5), forming an angle of about $14^{\circ}$ between the plane of the aromatic ring and the

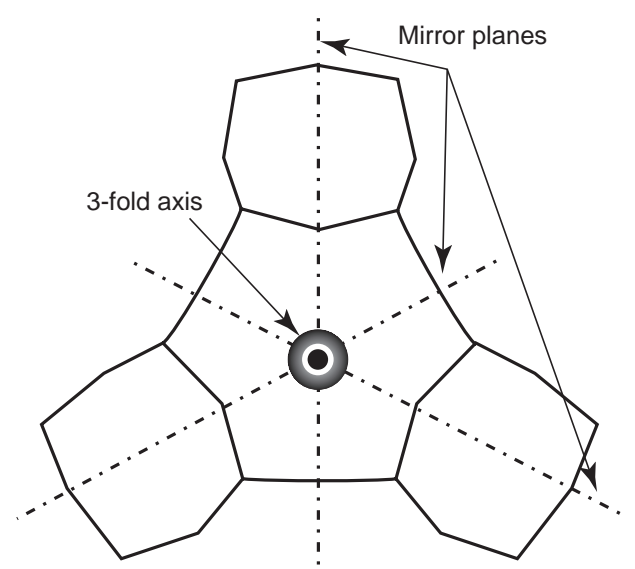

Figure 5

Three-fold axis and mirror planes in the supercage. plane of the nearby 6-ring window of the framework. A strong interaction between the aromatic ring and the cation is indicated by a short distance between the $\mathrm{Ba}(2)$ and the $\mathrm{C}$ atoms of the aromatic ring. In addition there is a short $\mathrm{D}_{\text {methyl }}-\mathrm{O}_{\text {framework }}$ distance of $0.22 \mathrm{~nm}$, which indicates that the para-xylene molecule at this site is strongly adsorbed. On average, 2.3 para-xylene molecules per supercage are located at this cationic adsorption site (Fig. 6).

The second adsorption site for para-xylene is a "noncationic" one. At this site, the para-xylene molecule is located in the plane of the 12-ring window between two supercages, and the centre of the aromatic ring is on the 3 -fold axis. There is no interaction between the aromatic ring of the para-xylene and cations, but the adsorption site seems to be stabilised by electrostatic interactions suggested by short $\mathrm{D}_{\text {methyl }} \mathrm{O}_{\text {framework }}$ distances of $0.25 \mathrm{~nm}$. One para-xylene molecule per supercage is on average located in this "noncationic" adsorption site (Table 4 and Fig. 7).

Selected distances between the para-xylene molecules at both sites and other atoms of the unit cell are also reported in Table 3.

\subsection{Conclusion on the Neutron Diffraction Study}

Partially hydrated zeolite BaX saturated with para-xylene was studied by a Rietveld refinement of neutron powder

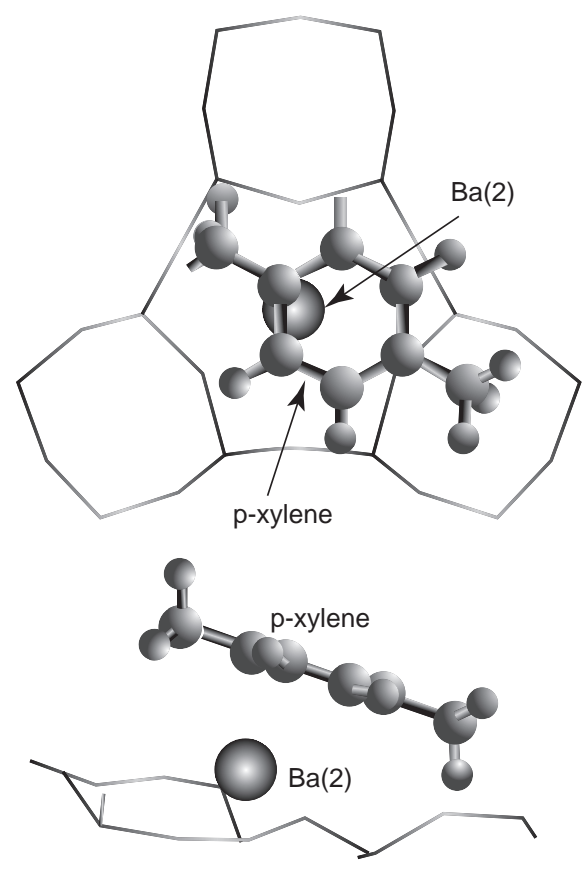

Figure 6

Cationic adsorption site for para-xylene in the partially hydrated zeolite BaX saturated with xylene. (a) Front view of the cationic site; (b) side view of the cationic site.

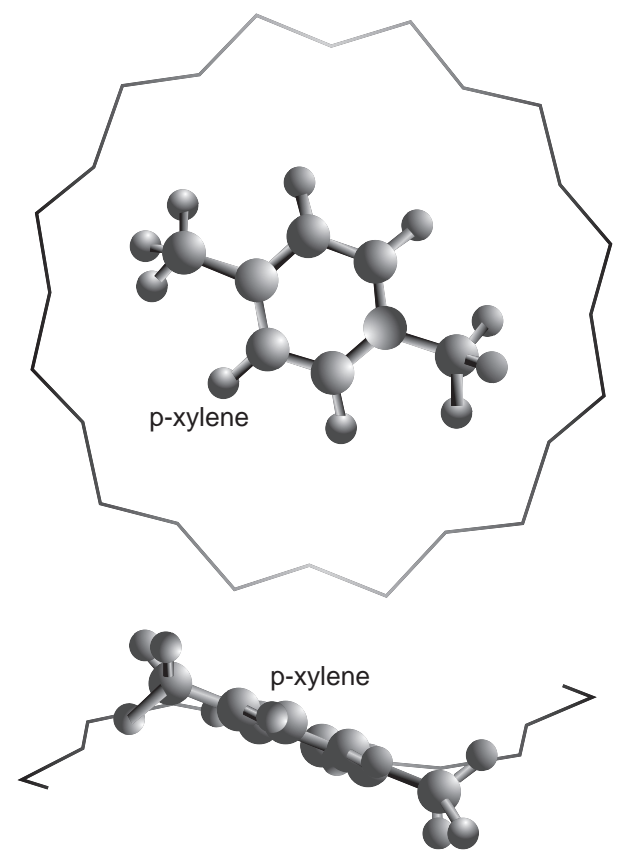

Figure 7

Non-cationic adsorption site for para-xylene in the partially hydrated zeolite BaX saturated with xylene. (a) Front view of the non-cationic site; (b) side view of the non-cationic site. 
diffraction. A clear and consistent picture of the distribution of the extra-framework species (cations, water and paraxylene molecules) has emerged.

Interesting elements of the structure of partially hydrated zeolite BaX saturated with para-xylene appeared to be:

- The cationic site SII for barium (in the supercage) is full (4 barium cations at site SII per supercage).

- An average of 2.3 barium cations per supercage are in interaction with 2.3 para-xylene molecules. The remaining barium cations in the supercage (on average 1.7 cations per supercage) are in interaction with water molecules: on average, each remaining barium cation is an adsorption site for 3 water molecules.

- A non-cationic adsorption site for para-xylene was found in the 12-ring window between 2 supercages. It is filled with, on average, 1.0 para-xylene molecule per supercage.

According to these occupancies, supercages of partially hydrated zeolite $\mathrm{BaX}$ saturated with para-xylene are highly filled (leaving very little free space between the molecules) and the confinement of molecules in the supercage may be one of the reasons explaining the selective adsorption observed in the industrial process.

Concerning the experimental technique, neutron powder diffraction is efficient but it is not an easy to handle technique:

- The access to the instrument (research nuclear reactor) is limited.

- The use of deuterated molecules, which are expensive and difficult to synthesise, is required (because of the non coherent scattering induced by the presence of hydrogen atoms in the sample).

- The data collection takes a long time (between 12 and 48 hours per sample) because of the low neutron flux delivered by the instrument. For the same reason, a large amount of sample is needed to have a good counting statistic.

- Because of the rapid decrease of signal with the increase of the temperature, low temperature recording is required and this is an important drawback for performing in situ measurement in the field of petrochemistry processes.

Nevertheless, structural studies of crystallised materials like molecular sieves by neutron powder diffraction are of great interest:

- First, as the nuclear scattering length for each element is not related to the atomic number, the diffracted signal is totally different from the diffracted signal in an X-ray powder diffraction experiment.

- Second, as carbon and deuterium atoms have high nuclear scattering lengths, it is possible to locate, with this technique, the hydrocarbons adsorbed in the structural porosity of the zeolite.

\section{STRUCTURAL CHARACTERISATION OF BICATIONIC X ZEOLITES BY ANOMALOUS X-RAY POWDER DIFFRACTION}

Using classical X-ray diffraction the location of light elements (typically carbon and hydrogen) in a heavier matrix $(\mathrm{Si}, \mathrm{Al}, \mathrm{O})$ is not easy even if the determination of the hydrofluorocarbon molecule (HFC-134) position in the channel of $\mathrm{NaY}$ zeolite has been achieved by this technique at low temperature (100 K) [14].

To obtain a better localisation of all atoms (such as cations in zeolites), we can use improved X-ray methods like resonant diffraction which has found many applications, in particular in macromolecular crystallography where it has become a routine technique for proteins structure determination [4]. In the petrochemistry field, this method was used to characterise divided solids (powder catalysts) [6][15]. In the following we present its interest in the characterisation of zeolitic molecular sieves [16].

\subsection{Aim of the Study}

Since compensating cations can influence the selective adsorption phenomenon in zeolite by their nature and their distribution on the different cationic sites, the addition of a second compensating cation can be a way to improve the selectivity of a molecular sieve in a given separation process. Thus, we must develop a structural tool which is efficient for the localisation of these different cations.

Numerous X-ray studies have been reported in the literature on cation distribution in monocationic zeolites in different experimental conditions. As an example, cation distributions in zeolites $\mathrm{X}$ fully exchanged with alkaline cations appear strongly dependent on the cation nature at high dehydration level. Cationic sites in the supercage (i.e. site SII, SIII and SIII') are highly populated in zeolite $\mathrm{NaX}$ as in zeolite KX whereas the site SI has been found empty [17] or almost empty [18] in zeolite NaX. On the contrary, 14 potassium cations (per unit cell) are located on this site in zeolite KX [19]. When the charge compensating cation is an alkaline-earth one, cation distributions are less affected by its nature: the cations are located mainly in sites I and II (exclusively for zeolite $\mathrm{CaX}$ [8][20]). The presence of residual water molecules often adsorbed in sodalite cages leads to an increase of site SI' population at the cost of site SI (zeolite CaX [21] and zeolite $\mathrm{SrX}$ [22]) or an increase of site SII' population (zeolite $\mathrm{MgX}$ [20]). At high water content, alkaline-earth cation distribution is characterised by:

- a low site SI population;

- and the occupancy of low symmetry sites in the supercage in a complex arrangement with adsorbed water molecules.

For bicationic zeolites, our knowledge of cation distribution remains restricted even in the easier cases (i.e. no adsorbed molecules in the framework). The greater the 
number of cationic types, the more the structure of the system is complex to study by classical X-ray diffraction (especially when the cations have close atomic numbers). This is the case for zeolite SrRbX where strontium and rubidium cations have the same number of electrons (36 electrons) and are, in this sense, impossible to distinguish by classical X-ray diffraction. As previously mentioned X-ray anomalous (or resonant) diffraction and neutron diffraction can provide an enhancement of the chemical selectivity (i.e. the contrast) which is, in general, of comparable intensity [4]. However in this particular case, strontium and rubidium have very close neutron scattering lengths $\left(b_{\mathrm{Rb}}=7.0 \times 10^{-15} \mathrm{~m}\right.$ and $\mathrm{b}_{\mathrm{Sr}}=7.1 \times 10^{-15} \mathrm{~m}$ ) and only the use of resonant diffraction may be helpful to unambiguously determine cation distribution in SrRbX sample.

In this present example, zeolite SrRbX was characterised during the in situ dehydration process: first at room temperature $(293 \mathrm{~K})$ and then at $523 \mathrm{~K}$ under a dry nitrogen flow.

\subsection{Experimental Section}

\subsubsection{Sample Preparation and Characterisation}

The zeolite SrRbX (unit cell composition determined by atomic absorption and X-ray fluorescence: $\mathrm{Na}_{4} \mathrm{Sr}_{32} \mathrm{Rb}_{16} \mathrm{Si}_{108} \mathrm{Al}_{84} \mathrm{O}_{384}$ ) was obtained by two successive ion exchange steps of the same synthetic zeolite $\mathrm{NaX}$ used for the preparation of the zeolite $\mathrm{BaX}$ (see 1.2.1). All the adsorption steps were performed on a micrometrical powder in aqueous solution using typical conditions [21, 23].

During the first ion exchange step a highly exchanged zeolite $\mathrm{SrX}$ was obtained (unit cell composition determined by atomic absorption and X-ray fluorescence: $\mathrm{Na}_{4} \mathrm{Sr}_{40} \mathrm{Si}_{108}$ $\mathrm{Al}_{84} \mathrm{O}_{384}$ ) and transformed during the second ion exchange in the zeolite $\mathrm{SrRbX}$.

The zeolite powder obtained was then placed in a $1 \mathrm{~mm}$ diameter glass capillary which was inserted in the sample holder of a purpose built in situ X-ray diffraction cell [22, 24].

The new in situ X-ray diffraction cell is presented in Figure 8 . It is directly mounted on a commercial goniometric head and composed of 3 parts. The first one consists in a motor inserted in a cylindrical cover which is used as an oscillating device for the X-ray cell. The second part is the sample holder which holds the glass capillary containing the sample. On the sample holder, two small tubes allow gas admission and extraction. The last part of the cell consists in an independent small tubular electric furnace which is $4 \mathrm{~cm}$ long and $1 \mathrm{~cm}$ in diameter.

With this cell, the zeolite $\mathrm{SrRbX}$ was dehydrated in situ at $523 \mathrm{~K}$ under dry nitrogen flux.

\subsubsection{Data Collection and Structure Refinement}

The powder patterns of the SrRbX sample were collected at two hydration steps, in situ, on the D2AM diffractometer at the European Synchrotron Radiation Facility (ESRF, Grenoble, France).

Three X-ray diagrams were recorded (close to and far from both strontium and rubidium X-ray K-absorption edges) for hydrated and dehydrated zeolite SrRbX (see Fig. 9). In this study the anomalous effect was used to distinguish rubidium and strontium cations which have the same number of electrons and which are impossible to distinguish by classical X-ray powder diffraction. Furthermore the anomalous effect was also used to distinguish cations and adsorbed molecules (residual water molecules) in the zeolite. Data

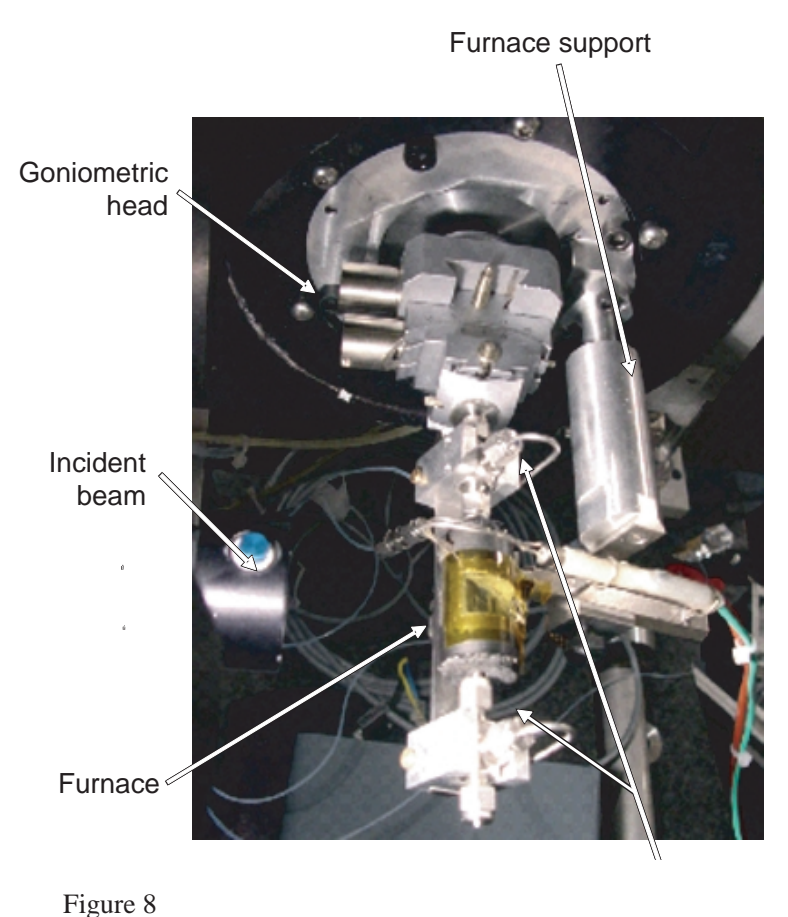

Figure 8

New in situ X-ray diffraction cell.

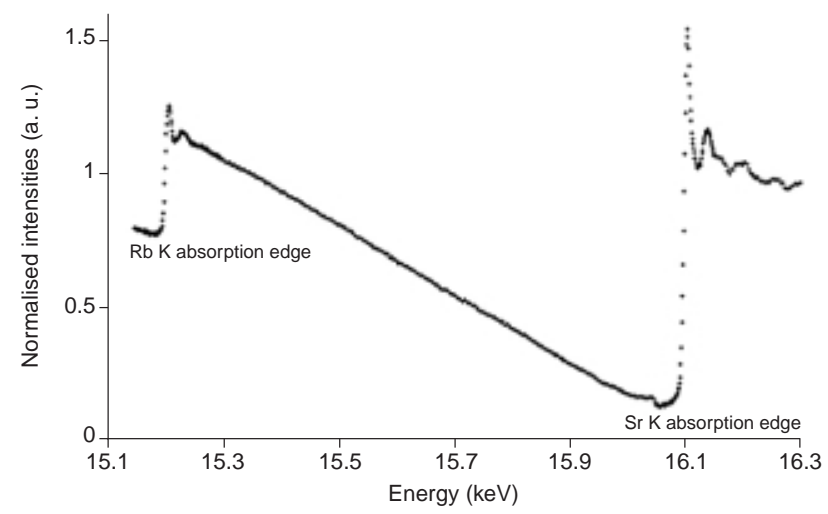

Figure 9

Absorption spectrum collected on hydrated SrRbX sample, at energies closed to rubidium $(15.202 \mathrm{keV})$ and strontium (16.106 keV) $\mathrm{K}$ absorption edges. 
collection was performed with care in order to obtain a good enough counting statistic and to collect a significant anomalous effect (in comparison with the statistical noise intensity).

The experimental conditions for anomalous diffraction studies are specified in Table 5. The experimental time is related to the number of steps (about 10,000) and to the counting time per step which cannot be reduced due to the oscillating time of the sample. For $2 \theta$ values lower than $30^{\circ}$, counting time equalled the duration for one sample oscillation (typically 1.6 to 2 s). At larger $2 \theta$ values, counting time per step was doubled when sample oscillation frequency remained unchanged.

The diffraction patterns were analysed by the Rietveld refinement method [10] using the FullProf software package [25]. As for the previous neutron diffraction study, the space group used was Fd3m. Residual water molecules were inserted in the structural model as $\mathrm{O}^{2-}$ ions (which have the same number of electrons as the $\mathrm{H}_{2} \mathrm{O}$ molecule) [21].

For each zeolite SrRbX hydration level, data analysis was performed in three steps [26]:

- The diagram, collected at the energy far from both rubidium and strontium $\mathrm{K}$ absorption edges (14.8 $\mathrm{keV}$ ), was first refined by the Rietveld method [10] to locate electrons in the structure (Fig. 10a). In other words, the crystallographic positions of the framework atoms were determined but it was impossible, at this stage, to attribute electrons located on a given cation site unambiguously to rubidium or strontium cations or to adsorbed water molecules. Only the interpretation of the chemical bond length between oxygen framework atoms and cation sites may suggest the chemical nature of the element on this site but no help comes from the classical diffraction pattern.

TABLE 5

Experimental and crystallographic data for anomalous X-ray diffraction studies on hydrated or in situ dehydrated zeolite SrRbX

\begin{tabular}{|c|c|c|}
\hline & Hydrated SrRbX & Dehydrated SrRbX \\
\hline $\begin{array}{l}\text { Data collection } \\
\text { diffractometer } \\
\text { temperature / K }\end{array}$ & $\begin{array}{c}\text { D2AM } \\
293\end{array}$ & $\begin{array}{c}\text { D2AM } \\
523\end{array}$ \\
\hline $\begin{array}{l}\text { energies / keV } \\
\text { (wavelengths / nm) }\end{array}$ & $\begin{array}{l}16.096(0.07703) \\
15.192(0.08161) \\
14.800(0.08377)\end{array}$ & $\begin{array}{l}16.096(0.07703) \\
15.192(0.08161) \\
14.800(0.08377)\end{array}$ \\
\hline $\begin{array}{l}\text { total time } / \mathrm{h} \\
\text { range } /{ }^{\circ} 2 \theta \\
\text { step size } /{ }^{\circ} 2 \theta\end{array}$ & $\begin{array}{c}20 \\
{[2.6 ; 54.1]} \\
0.006\end{array}$ & $\begin{array}{c}20 \\
{[2.6 ; 54.1]} \\
0.008\end{array}$ \\
\hline $\begin{array}{l}\text { Rietveld refinement } \\
\text { space group } \\
\text { lattice parameter / nm } \\
\text { number of observations / steps, } \mathrm{N}\end{array}$ & $\begin{array}{c}F d 3 m \\
2.5036 \\
8584\end{array}$ & $\begin{array}{c}F d 3 m \\
2.5144 \\
6439\end{array}$ \\
\hline number of contributing reflections & $\begin{array}{l}693 \\
588 \\
546\end{array}$ & $\begin{array}{l}702 \\
596 \\
552\end{array}$ \\
\hline $\begin{array}{l}\text { number of structural parameters }(\mathrm{P} 1) \\
\text { number of profile parameters }(\mathrm{P} 2)\end{array}$ & $\begin{array}{c}46 \\
0\end{array}$ & $\begin{array}{c}36 \\
0\end{array}$ \\
\hline $\mathrm{R}_{\mathrm{wp}}=\left\{\sum \mathrm{w}[\mathrm{y}(\mathrm{o})-\mathrm{y}(\mathrm{c})]^{2} / \sum \mathrm{wy}(\mathrm{o})^{2}\right\}^{1 / 2}$ & $\begin{array}{l}6.7 \\
6.7 \\
6.3\end{array}$ & $\begin{array}{l}8.1 \\
9.2 \\
9.1\end{array}$ \\
\hline $\mathrm{R}_{\text {Bragg }}=\sum|\mathrm{I}(\mathrm{o})-\mathrm{I}(\mathrm{c})| / \sum|\mathrm{I}(\mathrm{o})|$ & $\begin{array}{l}3.3 \\
3.3 \\
2.9\end{array}$ & $\begin{array}{l}1.9 \\
2.9 \\
3.8\end{array}$ \\
\hline $\mathrm{R}_{\exp }=\left[(\mathrm{N}-\mathrm{P} 1-\mathrm{P} 2) / \sum \mathrm{wy}(\mathrm{o})^{2}\right]^{1 / 2}$ & $\begin{array}{l}3.9 \\
2.6 \\
2.6\end{array}$ & $\begin{array}{l}2.8 \\
2.0 \\
2.4\end{array}$ \\
\hline
\end{tabular}




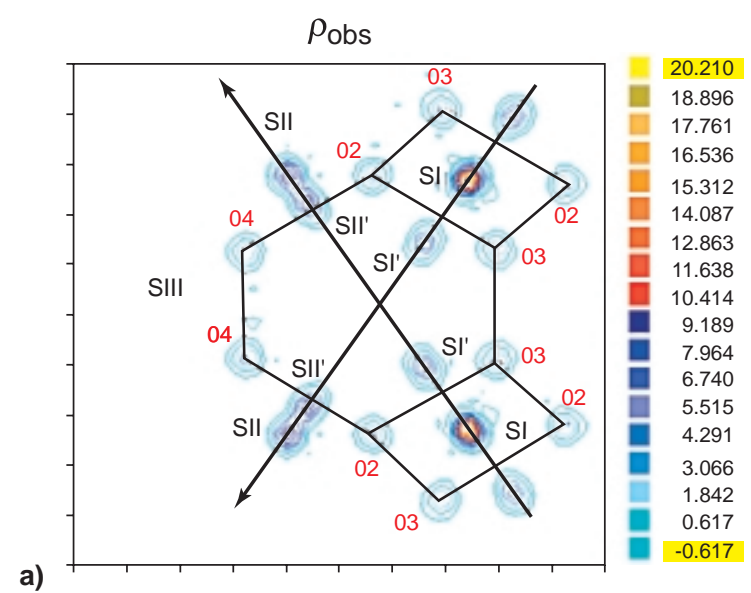

b)

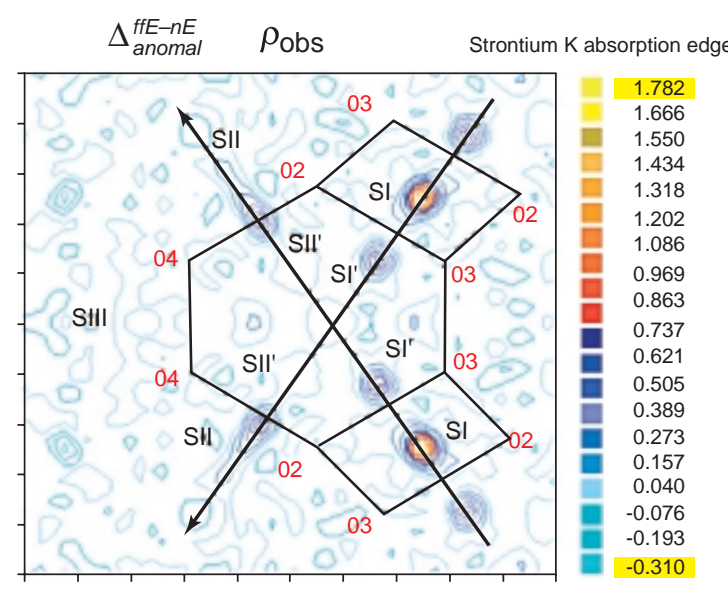

c)

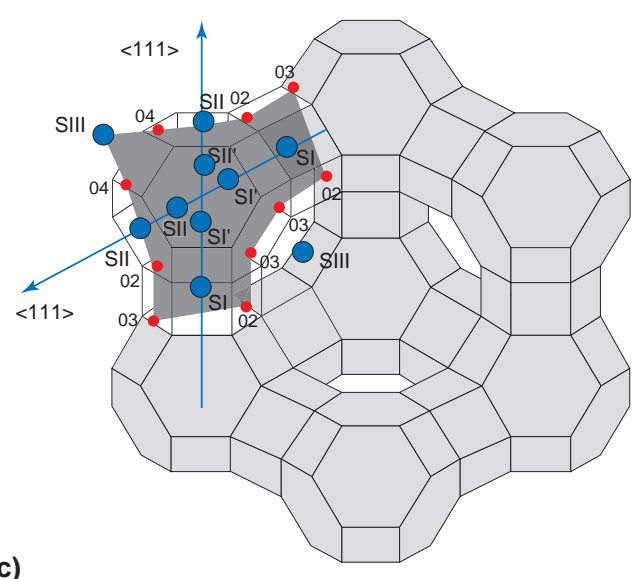

Figure 10

"Dispervive difference electron density maps": location of total electron density (a) and strontium cations (b) in the plane $\mathrm{P}$, which is defined by the intersection of two <111> axes, and represented in dark grey (c).

In this Figure, the sites I, I', II', II and III are noted respectively SI, SI', SII', SII and SIII.
- At the next step, the anomalous signal has been interpreted by the use of "Anomalous Fourier difference maps". These difference maps were calculated at $\mathrm{Sr}$ and $\mathrm{Rb} \mathrm{K}$ absorption edges (Fig. 10b) [26-28]: distributions of strontium and rubidium cations were then visualized. On this basis, $\mathrm{Rb}$ and $\mathrm{Sr}$ cation locations were included in the structural model and each occupancy rate was refined, based on the diffraction data collected far from both absorption edges $(14.8 \mathrm{keV})$ and from the anomalous signal.

- At the final step, careful simultaneous refinements of the three datasets (collected at three different energies) were performed. However, systematic comparison between measured and calculated anomalous Fourier maps and "anomalous difference diagrams" (Fig. 11) was used to verify the quality of the refined structure $[6,26]$.

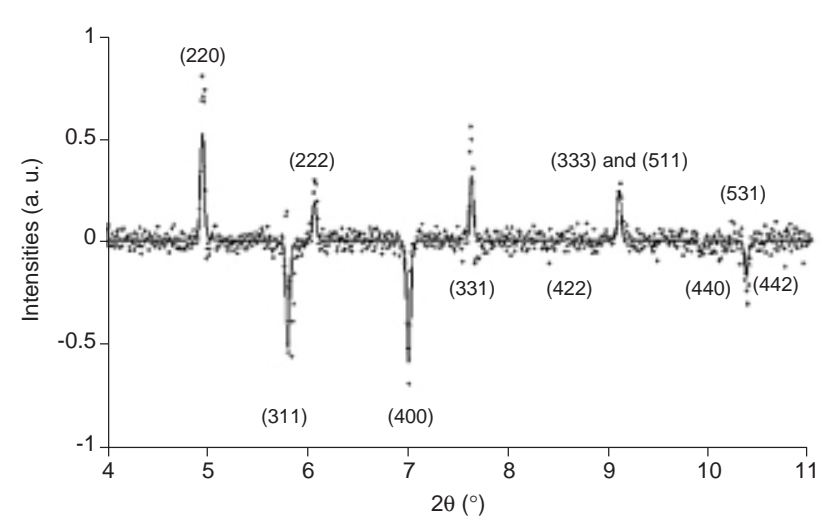

Figure 11

Comparison between measured and calculated X-ray powder "anomalous differential patterns" for dehydrated zeolite $\mathrm{SrRbX}$ at strontium $\mathrm{K}$ absorption edge. + experimental data; - calculated profile.

Comparisons of measured and calculated diagrams for hydrated and dehydrated zeolite SrRbX are shown in Figures 12 and 13 respectively. Rietveld refinement parameters are reported in Table 5. The refined structural parameters describing hydrated and dehydrated zeolite SrRbX are gathered in Table 6 and 7.

\subsection{Results}

\subsubsection{Description of the Structure}

In zeolite SrRbX, X-ray diffraction measurements showed a clear lattice parameter increase from $2.5036 \mathrm{~nm}$ in high hydration condition up to $2.5144 \mathrm{~nm}$ in dehydrated case, thus demonstrating the same behaviour as the parent zeolite SrX [22]. Whatever the hydration level, the average T-O distance 


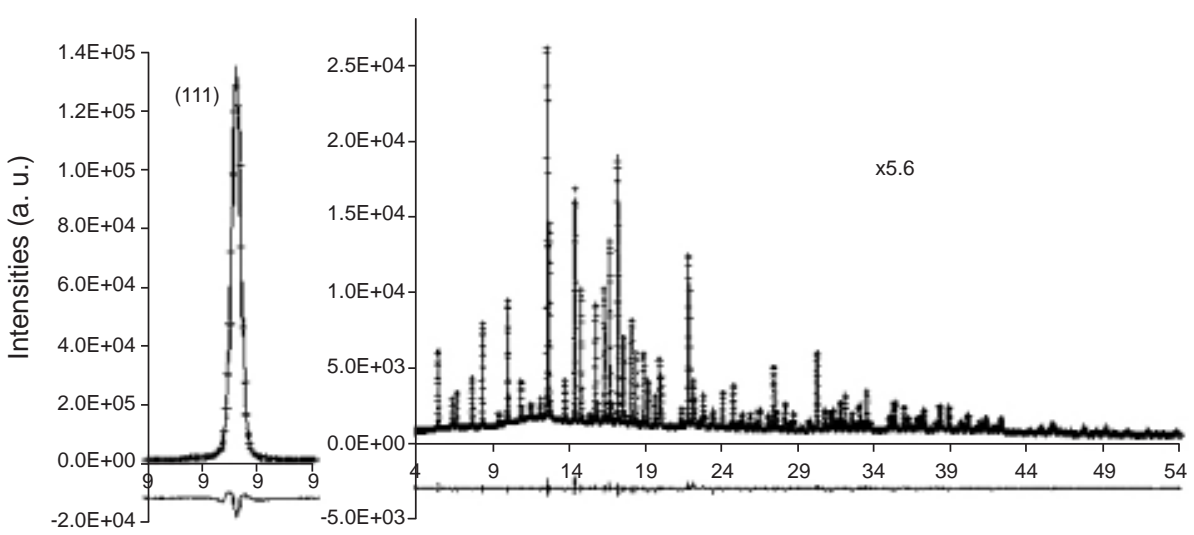

Figure 12

$2 \theta\left(^{\circ}\right)$

X-ray powder pattern and Rietveld plot for the refinement of hydrated zeolite SrRbX. Upper part: + experimental data; - calculated profile. Lower part: - difference between experimental and calculated profiles.

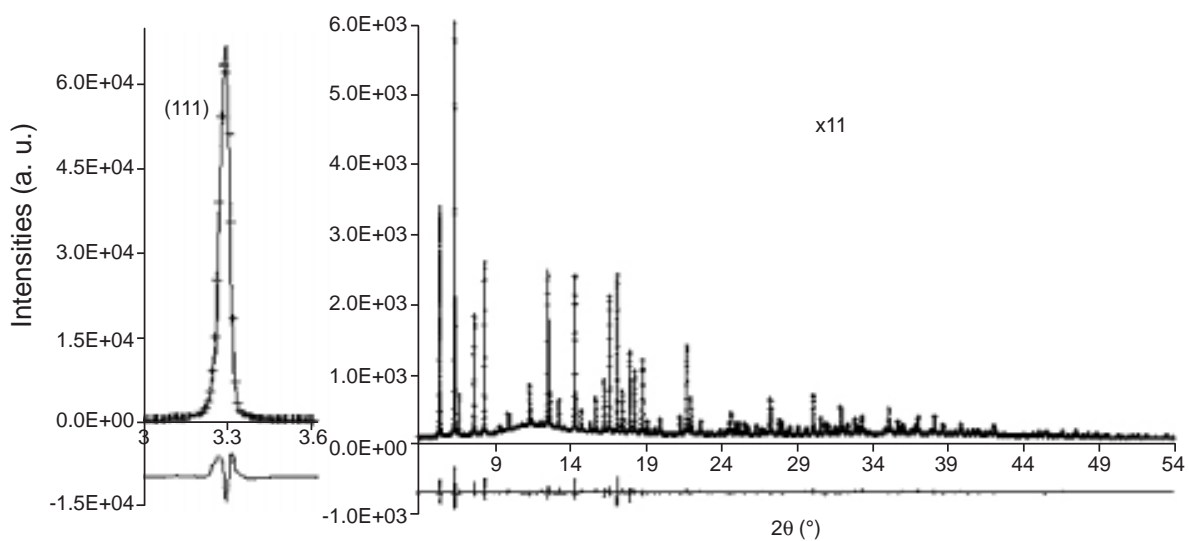

Figure 13

X-ray powder pattern and Rietveld plot for the refinement of dehydrated zeolite SrRbX. Upper part: + experimental data; - calculated profile. Lower part: - difference between experimental and calculated profiles.

has been found to be $0.166 \mathrm{~nm}$ and the average T-O-T angle is $144.0^{\circ}$.

The zeolite SrRbX crystallographic structure (see Table 6 and 7) appeared complex compared to zeolite BaX (see Table 2). In particular, the electron density description using cation sites required the introduction of different crystallographic positions.

However it must be noted that with water molecule loss:

- the distance from the centre of the hexagonal prism to the six O3 oxygen atoms (SI-O3) decreased from $0.291 \mathrm{~nm}$ to $0.276 \mathrm{~nm}$, indicating a modification of the atomic element occupying this site;

- the distance from site SI'a to O3 oxygen atoms (SI'a-O3) did not change significantly $(0.257 \mathrm{~nm}$ in the hydrated and
$0.256 \mathrm{~nm}$ in the dehydrated case), suggesting that the chemical nature of the scatterer on this site is the same in both conditions;

- the distance from site SIIa to O2 oxygen atoms (SIIa-O2) also remains unchanged $(0.246 \mathrm{~nm})$.

\subsubsection{Location of Strontium and Rubidium Cations}

Thanks to the anomalous effect it was possible to locate accurately both strontium and rubidium cations in zeolite $\mathrm{SrRbX}$ for the two hydration conditions. Results of this study are summarised on Figure 14.

In hydration conditions, $\mathrm{Sr}^{2+}$ cations appeared to occupy mainly site SI' (17.1 cations per unit cell) and low symmetry sites inside the supercage ( 8.0 cations). These sites are 
TABLE 6

Fractional coordinates, isotropic displacement factors U and population parameters PP for zeolite SrRbX highly hydrated

\begin{tabular}{|c|c|c|c|c|c|c|}
\hline Atom & $\begin{array}{c}\text { Position } \\
\text { multiplicity }\end{array}$ & $\mathrm{x}$ & $\mathrm{y}$ & $\mathrm{z}$ & $\mathrm{U}(\times 100)$ & $\mathrm{PP}$ \\
\hline SiAl & 192 & $-0.05485(3)$ & 0.12588 & $0.03590(3)$ & $1.7(0)$ & 1 \\
\hline $\mathrm{O}(1)$ & 96 & $-0.10680(6)$ & $-0.10680(6)$ & 0 & $3.3(0)^{\mathrm{a}}$ & 1 \\
\hline $\mathrm{O}(2)$ & 96 & $-0.00251(7)$ & $-0.00251(7)$ & $0.13944(7)$ & $3.3(0)^{\mathrm{a}}$ & 1 \\
\hline $\mathrm{O}(3)$ & 96 & $0.17161(6)$ & $0.17161(6)$ & $-0.03643(8)$ & $3.3(0)^{\mathrm{a}}$ & 1 \\
\hline $\mathrm{O}(4)$ & 96 & $0.18247(5)$ & $0.18247(5)$ & $0.32074(8)$ & $3.3(0)^{\mathrm{a}}$ & 1 \\
\hline $\mathrm{Rb}^{+}\left(1 \_\mathrm{a}\right)$ & 16 & 0 & 0 & 0 & $3.4^{\mathrm{b}}$ & $0.078(1)$ \\
\hline $\mathrm{Na}^{+}\left(1 \_b\right)$ & 32 & $0.0037(7)$ & $0.0037(7)$ & $0.0037(7)$ & $3.4^{\mathrm{b}}$ & 0.125 \\
\hline $\mathrm{Sr}^{2+}\left(1^{\prime}\right)$ & 32 & $0.06372(3)$ & $0.06372(3)$ & $0.06372(3)$ & 3.7 & $0.536(1)$ \\
\hline $\mathrm{O}^{-2}\left(2^{\prime}\right)$ & 32 & $0.16828(6)$ & $0.16828(6)$ & $0.16828(6)$ & $3.6(1)$ & 1 \\
\hline $\mathrm{Sr}^{2+}\left(2 \_\mathrm{a}\right)$ & 32 & $0.2295(9)$ & $0.2295(9)$ & $0.2295(9)$ & $1.8(1)^{\mathrm{c}}$ & $0.028(2)$ \\
\hline $\mathrm{Sr}^{2+}\left(2 \_\mathrm{b}\right)$ & 32 & $0.2487(2)$ & $0.2487(2)$ & $0.2487(2)$ & $1.8(1)^{\mathrm{c}}$ & $0.146(2)$ \\
\hline $\mathrm{Rb}^{+}\left(2 \_\mathrm{c}\right)$ & 32 & $0.2653(1)$ & $0.2653(1)$ & $0.2653(1)$ & $1.8(1)^{\mathrm{c}}$ & 0.282 \\
\hline $\mathrm{O}^{-2}\left(2 \_d\right)$ & 96 & $0.2728(4)$ & $0.2728(4)$ & $0.3089(11)$ & $1.8(1)^{\mathrm{c}}$ & $0.10(1)$ \\
\hline $\mathrm{Rb}^{+}\left(2 \_\mathrm{e}\right)$ & 192 & 0.2373 & 0.5015 & 0.0199 & $1.8(1) \mathrm{c}$ & 0.037 \\
\hline $\mathrm{O}^{-2}\left(3^{\prime} \_a\right)$ & 96 & $0.3198(2)$ & $0.1903(2)$ & $0.5602(2)$ & $12.5(0)^{\mathrm{d}}$ & $0.261(3)$ \\
\hline $\mathrm{Sr}^{2+}\left(3^{\prime}{ }_{-} \mathrm{b}\right)$ & 96 & $0.3198(2)$ & $0.1903(2)$ & $0.5602(2)$ & $12.5(0)^{\mathrm{d}}$ & 0.075 \\
\hline $\mathrm{O}^{-2}\left(3^{\prime} \_\mathrm{c}\right)$ & 192 & $-0.0318(11)$ & $-0.1331(7)$ & $0.2414(4)$ & 24.2 & $0.289(1)$ \\
\hline $\mathrm{O}^{-2}\left(3^{\prime} \_\mathrm{d}\right)$ & 96 & $-0.1543(3)$ & $-0.0957(3)$ & $0.3112(6)$ & 39.7 & $0.282(3)$ \\
\hline $\mathrm{O}^{-2}\left(3^{\prime} \_\mathrm{e}\right)$ & 96 & $-0.1606(2)$ & $-0.1606(2)$ & $0.2006(3)$ & 21.5 & $0.605(4)$ \\
\hline $\mathrm{O}^{-2}\left(3^{\prime}-\mathrm{f}\right)$ & 96 & 0.0000 & 0.0000 & $0.3980(16)$ & 21.5 & $0.179(22)$ \\
\hline $\mathrm{O}^{-2}\left(3^{\prime}, \mathrm{g}\right)$ & 192 & $0.6737(8)$ & 0.0000 & $0.3103(9)$ & 19.0 & $0.210(3)$ \\
\hline $\mathrm{Sr}^{2+}\left(3^{\prime} \_\mathrm{h}\right)$ & 16 & 0.2500 & 0.2500 & 0.5000 & $7.5(8)$ & 0.052 \\
\hline
\end{tabular}

a-d: Parameters with the same superscript were constrained to be equal.

TABLE 7

Fractional coordinates, isotropic displacement factors $\mathrm{U}$ and population parameters PP for highly dehydrated zeolite $\mathrm{SrRbX}$

\begin{tabular}{|c|c|c|c|c|c|c|}
\hline Atom & $\begin{array}{c}\text { Position } \\
\text { multiplicity }\end{array}$ & $\mathrm{x}$ & $\mathrm{y}$ & $\mathrm{z}$ & $\mathrm{U}(\times 100)$ & $\mathrm{PP}$ \\
\hline SiAl & 192 & $-0.05618(4)$ & $0.12442(5)$ & $0.03526(5)$ & $1.8(0)$ & 1 \\
\hline $\mathrm{O}(1)$ & 96 & $-0.10942(8)$ & $0.10942(8)$ & 0 & $2.9(0)^{\mathrm{a}}$ & 1 \\
\hline $\mathrm{O}(2)$ & 96 & $-0.00357(9)$ & $-0.00357(9)$ & $0.13734(12)$ & $2.9(0)^{\mathrm{a}}$ & 1 \\
\hline $\mathrm{O}(3)$ & 96 & $0.18103(8)$ & $0.18103(8)$ & $-0.03782(11)$ & $2.9(0)^{\mathrm{a}}$ & 1 \\
\hline $\mathrm{O}(4)$ & 96 & $0.17807(9)$ & $0.17807(9)$ & $0.31453(14)$ & $2.9(0)^{\mathrm{a}}$ & 1 \\
\hline $\mathrm{Sr}^{2+}\left(1 \_\mathrm{a}\right)$ & 16 & 0 & 0 & 0 & $1.9(1)^{b}$ & $0.49(5)$ \\
\hline $\mathrm{Sr}^{2+}\left(1 \_b\right)$ & 32 & $0.0092(17)$ & $0.0092(17)$ & $0.0092(17)$ & $1.9(1)^{\mathrm{b}}$ & $0.09(3)$ \\
\hline $\mathrm{Na}^{+}\left(1^{\prime} \_\mathrm{a}\right)$ & 32 & $0.0548(17)$ & $0.0548(17)$ & $0.0548(17)$ & $3.7(2)^{\mathrm{c}}$ & $0.14(3)$ \\
\hline $\mathrm{Sr}^{2+}\left(1^{\prime} \_b\right)$ & 32 & $0.0638(2)$ & $0.0638(2)$ & $0.0638(2)$ & $3.7(2)^{\mathrm{c}}$ & $0.24(1)$ \\
\hline $\mathrm{Rb}^{+}\left(1^{\prime} \_\mathrm{c}\right)$ & 32 & $0.0861(20)$ & $0.0861(20)$ & $0.0861(20)$ & $3.7(2)^{\mathrm{c}}$ & $0.021(3)$ \\
\hline $\mathrm{O}^{-2}\left(2^{\prime} \_\mathrm{a}\right)$ & 32 & $0.1473(7)$ & $0.1473(7)$ & $0.1473(7)$ & $7(1)^{\mathrm{d}}$ & $0.150(5)$ \\
\hline $\mathrm{O}^{-2}\left(2^{\prime} \_b\right)$ & 32 & $0.1734(12)$ & $0.1734(12)$ & $0.1734(12)$ & $7(1)^{d}$ & $0.146(5)$ \\
\hline $\operatorname{Sr}^{2+}\left(2 \_a\right)$ & 32 & $0.2197(6)$ & $0.2197(6)$ & $0.2197(6)$ & $2.8(1)^{\mathrm{e}}$ & $0.18(1)$ \\
\hline $\mathrm{Sr}^{2+}\left(2 \_b\right)$ & 32 & $0.2325(5)$ & $0.2325(5)$ & $0.2325(5)$ & $2.8(1)^{\mathrm{e}}$ & $0.25(1)$ \\
\hline $\mathrm{Rb}^{+}\left(2 \_\mathrm{c}\right)$ & 32 & $0.2550(1)$ & $0.2550(1)$ & $0.2550(1)$ & $2.8(1)^{\mathrm{e}}$ & $0.422(3)$ \\
\hline $\mathrm{Rb}^{+}(3)$ & 48 & $0.4194(10)$ & 0.125 & 0.125 & 9.1 & $0.045(5)$ \\
\hline
\end{tabular}

a-e: Parameters with the same superscript were constrained to be equal. 

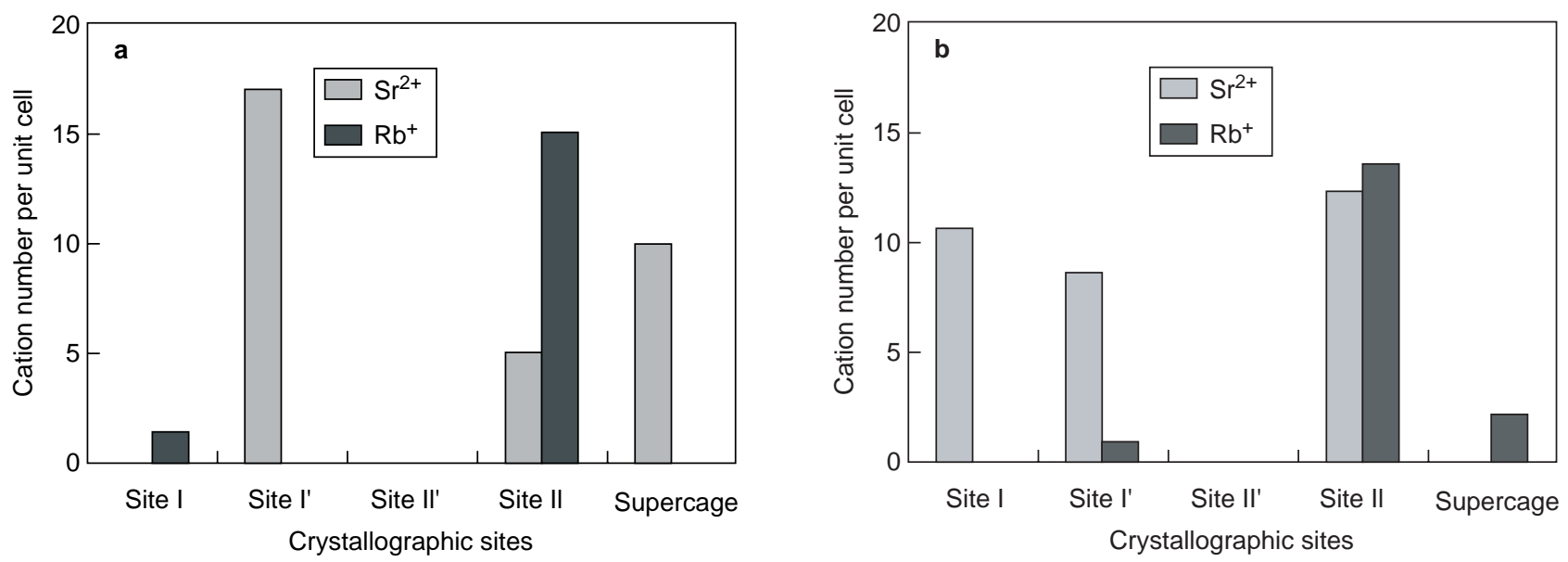

Figure 14

Distribution of both strontium and rubidium cations in both hydrated (a) and highly dehydrated SrRbX (b) zeolite.

labelled "supercage" in Figure 14. On site SII, in addition to the 5.9 remaining $\mathrm{Sr}^{2+}$ in the unit cell, $15.8 \mathrm{Rb}^{+}$cations have been located. Non-exchanged $\mathrm{Na}^{+}$cations occupy the site SI with residual $\mathrm{Rb}^{+}$cations [21].

Strong dehydration of $\mathrm{SrRbX}$ zeolite at $523 \mathrm{~K}$ is attested by the limited number of water molecules ( 9.6 molecules per unit cell) remaining in the structure. This departure has induced a strong $\mathrm{Sr}^{2+}$ cation distribution evolution whereas the $\mathrm{Rb}^{+}$cation distribution seemed less affected. Indeed, in these conditions, $\mathrm{Sr}^{2+}$ cation occupy the high symmetry sites I (10.7 cations), I' (7.7 cations) and II (13.6) whereas the main part of $\mathrm{Rb}^{+}$are still located on site SII (13.5). Population of site SIII (2.1), increased and showed the presence of $\mathrm{Rb}^{+}$cations in the supercage. On contrary, a limited fraction of these alkaline cations has migrated to sodalite cage on site SI' (0.7).

\subsection{Conclusion on the Anomalous X-ray Diffraction Study}

Zeolite $\mathrm{SrRbX}$ was studied by anomalous X-ray diffraction in two different equilibrium states. The first was obtained at $293 \mathrm{~K}$ (when the zeolite was hydrated) whereas the second was obtained after an in situ dehydration of the zeolite at $523 \mathrm{~K}$. In both cases, accurate information on the variation of the cationic distribution with the experimental conditions was obtained. Interesting elements in the cationic distribution of hydrated and dehydrated zeolite $\mathrm{SrRbX}$ were found to be:

- the strong $\mathrm{Sr}^{2+}$ cation distribution evolution;

- the low dependence of $\mathrm{Rb}^{+}$cation distribution on the number of water molecules;

- the competitive population of site SII by $\mathrm{Sr}^{2+}$ and $\mathrm{Rb}^{+}$ cations.
Note that the in situ set-up was designed to study molecular sieves under dynamic hydrocarbon molecule adsorption conditions. Preliminary investigations on cation distribution of this $\mathrm{SrRbX}$ zeolite have been performed under working conditions i.e. at $448 \mathrm{~K}$ under a nitrogen flux saturated with para-xylene vapour [29] and show the potentialities of such analyses.

Even if X-ray diffraction is not the best technique to locate adsorbed light molecules (i.e. composed of carbon, hydrogen and oxygen atoms), the experimentally refined distribution of adsorbed molecules (water and para-xylene molecules) is consistent with the physical-chemistry of the system. Organic molecules appeared to have a significant contribution in the X-ray diagram which can be exploited thanks to the precise cationic attribution of electronic density given by the anomalous effect. In principle, the use of anomalous diffraction may indirectly provide an additional accuracy in the location of these molecules: the correlation, during the refinement, between the diffracted signal of these molecules and the residue, resulting from inappropriate attribution of electronic density to element type or location, should be limited.

Concerning the experimental technique, anomalous X-ray diffraction is not an easy to handle technique:

- The access to the instrument (synchrotron) is limited.

- The recording of the data takes a long time (about 7 hours per energy for the present experiment) because accurate $\mathrm{X}$-ray diagrams close to and far from adsorption edge of an element are required to measure and to interpret the anomalous effect. Recent advances at synchrotron radiation facilities concern the increasing efficiency of new one or two dimensional detectors, (for example the "microstrips" detector [30] or "pixel" detector [31]). For $\mathrm{X}$-ray powder diffraction measurements, patterns can be 
collected with a small 2 dimensional detector. First tests of anomalous diffraction performed on powders, have shown a large decrease in duration of the data collection (by a factor fifteen up to twenty) without any cost of data quality. This improvement will lead in the very near future to an increase in the number of measured samples during a given experience time.

Nevertheless, structural studies of crystallised materials like molecular sieves by anomalous X-ray diffraction are of great interest because:

- X-ray diffraction is compatible with in situ characterisation under temperature.

- The anomalous X-ray powder diffraction technique brings chemical selectivity, that is to say contrast. For complex systems, like bicationic zeolite, such chemical sensitivity is necessary to distinguish between two species (cations or adsorbed molecules) with close atomic number (for example $\mathrm{Sr}^{2+}$ and $\mathrm{Rb}^{+}$which have the same number of electrons) or between two cations located at the same site.

- Due to X-ray high flux, small amounts of powder are sufficient to perform the structural characterisation.

\section{DISCUSSION}

\subsection{Contrast}

To compare, with the same normalized tool, the efficiency of neutron powder diffraction and X-ray anomalous powder diffraction in contrast studies, the following expression must be considered [32]:

$$
\text { contrast }=2 \times \frac{f_{a}-f_{b}}{f_{a}+f_{b}}
$$

where $f_{a}$ and $f_{b}$ are respectively the real part of the atomic scattering factors (or the coherent neutrons scattering lengths) of two elements labelled a and b. The scattering contrast is the ratio of the difference between scattering factors of two elements, to their average. In Figure 15, this expression is plotted against diffraction angles at different energy for two samples.

As shown in Figure 15a, X-ray anomalous diffraction is more appropriate to discriminate $\mathrm{Sr}$ and $\mathrm{Rb}$ cation distribution in SrRbX zeolite.

Another comparative analysis of the contrast efficiency of resonant $\mathrm{X}$-ray scattering relative to neutron diffraction was reported by Warner et al. in $\mathrm{Co}_{2} \mathrm{Fe}\left(\mathrm{PO}_{4}\right)_{2}$ [33]. They refined occupancies of the two sites possible for Co and/or Fe. In this compound, $\mathrm{Fe}$ and $\mathrm{Co}$ neutron scattering lengths are different $\left(\mathrm{b}_{\mathrm{Fe}}=9.510^{-15} \mathrm{~m}, \mathrm{~b}_{\mathrm{Co}}=2.510^{-15} \mathrm{~m}\right)$ and at $9 \mathrm{eV}$ before the Fe K edge the Fe resonant f' factor reaches a value close to -8 e.u., increasing the difference between $\mathrm{Fe}$ and $\mathrm{Co}$ scattering factors $\left(\mathrm{Z}_{\mathrm{Fe}}=26, \mathrm{Z}_{\mathrm{Co}}=27\right)$. For both refinements, the resulting $\mathrm{Fe} / \mathrm{Co}$ occupancies are in agreement at the level of two estimated standard deviations (esds'). These esds' are nearly the same (1-2\%) for the two radiations and confirm the equivalence of both techniques (Fig. 15b). The same remark has been made for the discrimination of $\mathrm{Ga}$ and $\mathrm{Ge}$ population in the clathrate $\mathrm{Sr}_{8} \mathrm{Ga}_{16} \mathrm{Ge}_{30}$ [32].

It should be noted that for neutron data, scattering lengths can present large variations between elements, and in particular the contrast can be tremendously improved for a compound with an atom having a negative neutron scattering length. This was demonstrated by Reimers et al. in the intermetallic compound $\left(\mathrm{Mn}_{1-\mathrm{x}} \mathrm{Cr}_{\mathrm{x}}\right) \mathrm{Sb}$ where the neutron scattering lengths are extremely different with a negative value for $\mathrm{Mn}\left(\mathrm{Z}_{\mathrm{Cr}}=24, \mathrm{~b}_{\mathrm{Cr}}=3.5210^{-15} \mathrm{~m} ; \mathrm{Z}_{\mathrm{Mn}}=25, \mathrm{~b}_{\mathrm{Mn}}=\right.$ $\left.-3.7310^{-15} \mathrm{~m}\right)$ [34]. In this case, the above defined value for
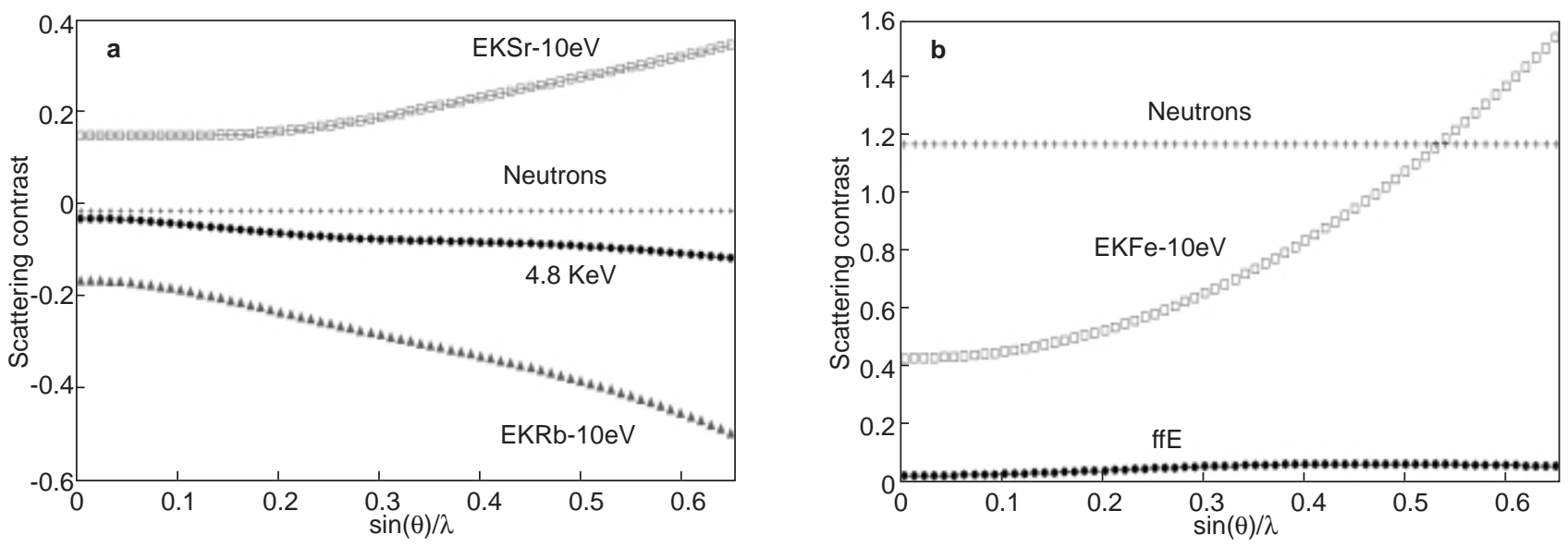

Figure 15

Evolution of the scattering contrast provided by neutron powder diffraction or X-ray anomalous diffraction to determine $\mathrm{Sr}$, $\mathrm{Rb}$ distributions in the zeolite $\mathrm{SrRbX}$ (a), and $\mathrm{Co}$ and $\mathrm{Fe}$ distributions in $\mathrm{Co}_{2} \mathrm{Fe}\left(\mathrm{PO}_{4}\right)_{2}$ [32] (b). 
scattering contrast is 34.5 (at diffraction angle zero): the value can be compared to the maximum values reported on Figure $15 \mathrm{a}$ and $\mathrm{b}$ that do not exceed 2.

In conclusion, the more efficient powder contrast method to characterise accurately a powdered sample cannot be defined a priori regardless of its chemical composition, it depends mainly on atom specificities ( $Z$ number, its absorption edge, isotopes, etc.).

\subsection{Requirements for Contrast Measurements}

The imaginary anomalous (or resonant) factor f'(E) is proportional to E. $\mu(\mathrm{E})$ (with $\mu(\mathrm{E})$ the absorption coefficient of the sample) and displays similar energy variation to the absorption itself. Since the real anomalous (or resonant) factor $\mathrm{f}^{\prime}(\mathrm{E})$ and the imaginary anomalous factor $\mathrm{f}^{\prime}(\mathrm{E})$ are related by the Kramers-Kronig relation [35, 36], f'(E) also displays large variations with energy close to the edge. Such variations (sharp resonance peak, energy shift of the edge position, preedge features, etc.) are related to the chemical nature of the sample and its local structure (atom, valence state, site symmetry,etc.). This sensitivity of the resonant diffraction to atomic chemical states and environments gives a small taste of the power of this method (as it is used for DAFS studies [4]) but also of its complexity. Thus a contrast resonant experiment must follow a few experimental requirements:

- Resonant scattering contribution is important only near absorption edges and the variation of this resonant scattering contribution close to the edge of a given atom can induce a variation of the contribution of this specific atom to diffracted intensities.

- Absorption is larger after the edge and can induce systematic errors in diffracted data. Thus the energy (or wavelength) of the incoming X-ray beam can affect the quality of the structural determination and must be chosen carefully: before and close to the edge.

- The chemical sensitivity of resonant scattering factors implies an experimental determination of $\mu(E), f$ '(E) and $f^{\prime}(E)$ on the same sample, with the same experimental setup and the same energy resolution as used for the resonant data collection.

- A precise energy calibration is necessary and, for the experiment performed close to the edge, a better accuracy is obtained by collecting data at 3 to $10 \mathrm{eV}$ before the edge.

- Systematic errors (sample absorption, surface roughness, occupancy/Debye Waller factor/scale factor correlations, etc.) could degrade the accuracy of the method. This effect can be minimized by using several patterns collected at energies close to different atoms of the sample [32].

- The resonant contribution is relatively weak and its use requires a more complex but efficient analysis by means of "dispersive difference electron density maps" and "anomalous differential patterns".
Neutron flux is low and neutron scattering power varies with atomic isotopes, thus a contrast neutron experiment must follow a few experimental requirements:

- Isotopic replacement is often needed (and expensive) for contrast studies. If different samples with different contrasts are needed, samples can present slightly different compositions, possibly different from those used in industrial processes.

- The sample must be large and the data collection time is long, thus in situ conditions cannot be achieved.

- As anomalous (or resonant) diffraction is suitable only for elements with $Z>20$, neutron is the key probe to localise light elements.

To solve neighbouring-element problems, we need a complete and accurate pattern up to high $\sin \theta / \lambda$. On one side, the $2 \theta$ resolution of a neutron diffractometer is worse, in many cases, than those of synchrotron radiation ones and a huge reflection overlapping occurs at high $\sin \theta / \lambda$. On the other side, the X-ray scattering factors decrease versus $\sin \theta / \lambda$. Thus, in both cases we need a data collection with very good statistics even at high $\sin \theta / \lambda$. However counting time should not be increased excessively so that estimated standard deviations on refined parameters (for example atomic positions) keep a physical meaning $[37,38]$.

\subsection{In situ Powder Diffraction Measurements}

Neutron powder diffraction enables the characterisation of the adsorbed phase in molecular sieves. Indeed an accurate structural study of meta- and para-xylene co-adsorbed in the partially hydrated zeolite $\mathrm{BaX}$ sample has been performed [9]. However this measurement was carried out at $4 \mathrm{~K}$ and the use of higher temperature would be inappropriate: it would induce a non negligible decrease of data quality. It is clear that the precise location of hydrocarbon molecules can only be determined under static adsorption conditions: no gaseous or liquid hydrocarbon can flow through zeolitic powder at this temperature.

Thanks to the in situ analyses of dehydrated SrRbX (reported in section 2), we have shown that X-ray powder diffraction could be used to characterize the cation distribution of a given molecular sieve at working temperature or even higher and under dynamic conditions. Moreover preliminary investigations on cation distribution of this zeolite $\mathrm{SrRbX}$ have been performed under working conditions i.e. at $448 \mathrm{~K}$ under a nitrogen flux saturated with para-xylene vapour [29].

It must be underlined, that presently the best contrast powder method available to characterise cation distribution of a bicationic zeolite under working conditions (temperature and dynamic adsorption conditions and small size sample) is anomalous X-ray diffraction whatever the scattering contrast between the two cations offered by neutrons. 
However hydrocarbon molecules may be difficult to locate by X-ray diffraction and the opportunity to introduce at the first step of the refinement an assumption of atomic positions, previously determined by neutron powder diffraction performed on the same molecular sieves, under $e x$ situ conditions, even at low temperature, would be very helpful.

\section{CONCLUSION}

In this contribution, it has been shown that powder diffraction is the key technique to characterize both hydrocarbon molecule adsorption sites and cation distribution in zeolitic molecular sieves. These measurements can give a unique opportunity to understand, at the atomic scale, the behaviour of $\mathrm{X}$ zeolites in a given separation process.

If additional scattering contrast is required to determine accurately the crystallographic structure of these molecular sieves, two complementary methods can be used: either neutron diffraction or anomalous X-ray diffraction. In the present article, their interests have enabled respectively location of two adsorption sites (one cationic and the other one non cationic) for para-xylene molecules adsorbed in partially hydrated zeolite $\mathrm{BaX}$, and description of the different evolution with hydration level in zeolite $\mathrm{SrRbX}$ of $\mathrm{Sr}^{2+}$ (extremely affected) and $\mathrm{Rb}^{+}$(almost unaffected) cations.

Both neutron and resonant diffraction can be used to determine accurately atomic positions. It is possible to extract the contribution of a single element in complex mixed powders. However this information has a price: it requires sophisticated tools (either neutron facilities or synchrotron radiation rings). The accuracy of the results has been underlined but the difficulties in the data analysis can not be neglected. Therefore the use of these powerful methods must be restricted to the study of a limited number of molecular sieves in a limited number of temperature and adsorption conditions. However contrast powder diffraction analyses appear fully complementary with the work undertaken in the field of molecular simulations where significant advances have occurred in the codes and the potentials $[39,40]$.

\section{REFERENCES}

1 Neuzil, R. (1971) US patent 3, 558, 730.

2 Meier, W.M., Olson, D.H. and Baerlocher, Ch. (1996) Atlas of Zeolites Structure Types, 4th edition, Elsevier, London.

3 Barrer, R.M. (1978) Zeolites and Clay Minerals as Sorbent and Molecular Sieves, Academic Press, New-York.

4 Hodeau, J.L., Favre-Nicolin, V., Bos, S., Renevier, H., Lorenzo, E. and Bérar, J.F. (2001) Resonant Diffraction. Chem. Rev., 101, 1843.

5 Cox, D.E. and Wilkinson, A.P. (1994) in Resonant Anomalous Diffraction X-ray Scattering, Materlik, G., Sparks, C.J. and Fischer, K., Eds., Elsevier Science B.V., Amsterdam, 195.
6 Waseda, Y. Springer Verlag in modern physics, 87 (2000): Heidelberg, Springer-Verlag.

7 Fitch, A.N., Jobic, H. and Renouprez, A. (1986) Localisation of Benzene in Sodium-Y Zeolite by Powder Diffraction. J. Phys. Chem., 90, 1311.

8 Vitale, G., Bull, L.M., Morris, R.E., Cheetham, A.K., Toby, B.H., Coe, C.G. and Mac Dougall, J.E. (1995) Combined Neutron and X-ray Powder Diffraction Study of Zeolite Ca LSX and ${ }^{2} \mathrm{H}$ NMR Study of its Complex with Benzene. J. Phys. Chem., 99, 16087.

9 Pichon, C. (1999) Étude structurale et énergétique de l'adsorption des isomères para et meta du xylène dans la zéolithe $\mathrm{BaX}$. Caractérisation par diffraction des neutrons et thermodésoprtion programmée. PhD Thesis/Thèse, Université de Bourgogne.

10 Rietveld, H.M. (1969) A Profile Refinement Method for Nuclear and Magnetic Structures. J. Appl. Crystallogr., 2, 165.

11 Larson, A.C. and Von Dreele, R.B. (1994) GSAS General Structure Analysis System, LAUR 86-748, Los Alamos National Laboratory: Los Alamos NM.

12 Mellot, C. (1993) Caractérisation structurale de l'adsorption des isomères para- et méta- du xylène dans des zéolithes de type X. PhD Thesis/Thèse, Université de Paris VI.

13 Descours, A. (1997) Adsorption des isomères para- et métadu xylène dans des zéolithes $\mathrm{NaX}$ et $\mathrm{BaX}$. Étude des relations propriétés-structure. PhD Thesis/Thèse, Université de Bourgogne.

14 Grey, C.P., Poshni, F.I., Gualtieri, A.F., Norby, P., Hanson, J.C. and Corbin, D.R. (1997) Combined MAS NMR and Xray Powder Diffraction Structural Characterization of Hydrofluorocarbon-134 Adsorbed on Zeolite NaY: Observation of Cation Migration and Strong Sorbate-Cation Interactions. J. Am. Chem. Soc., 119, 1981.

15 Bazin, D., Guzci, L. and Lynch, J. (2002) Anomalous Wide Angle X-ray Scattering (AWAXS) and Heterogenous Catalysts. Applied Catalysis A: General, 226, 87.

16 Bazin, D., Lynch, J. and Ramos-Fernandez, M. (2003) X-ray Absorption Spectroscopy and Anomalous Wide Angle X-ray Scattering: Two Basic Tools in the Analysis of Heterogeneous Catalysts. Oil \& Gas Science and TechnologyRev. IFP, 58, 6, 667.

17 Zhu, L. and Seff, K. (1999) Reinvestigation of the Crystal Structure of Dehydrated Sodium Zeolite X. J. Phys. Chem., B103, 9512.

18 Olson, D.H. (1995) The Crystal Structure of Dehydrated NaX. Zeolites, 15, 439.

19 Zhu, L. and Seff, K. (2000) Cation Crowding in Zeolite. Reinvestigation of the Crystal Structure of Dehydrated Potassium-Exchanged Zeolite X. J. Phys. Chem., B104, 8946.

20 Yeom, Y.H., Jang, S.B., Song, S.H., Kim, Y. and Seff, K. (1997) Three Crystal Structures of Vacuum-Dehydrated Zeolite X. J. Phys. Chem., B101, 6914.

21 Palancher, H. (2004) Caractérisation in situ par diffraction anomale de la distribution cationique de zéolithes $\mathrm{X}$ bicationiques dans des conditions proches de leur utilisation industrielle. PhD Thesis/Thèse, Université de Grenoble I.

22 Palancher, H., Pichon, C., Rebours, B., Hodeau, J.L., Lynch, J., Bérar, J.F., Prevot, S., Conan, G. and Bouchard, C. (2005) A Cell for in situ Dynamic X-ray Diffraction Studies: Application to the Dehydration of Zeolite SrX. J. Appl. Crystallogr., 38, 370.

23 Olson, D. (1970) A Reinvestigation of the Crystal Structure of the Hydrated Zeolite NaX. J. Phys. Chem.,74, 2758. 
24 Palancher, H., Pichon, C., Prévot, S., Conan, G., Hodeau, J.L. and Bérar, J.F. (2003) Dispositif d'analyse de poudre par diffraction des rayons X. Brevet d'invention Français $\mathrm{n}^{\circ}$ 03/07 641 .

25 Rodriguez-Cavajal, J. (1990) In Collected Abstracts of Powder Diffraction Meeting, Toulouse France, 127.

26 Palancher, H., Hodeau, J.L., Pichon, C., Bérar, J.F., Lynch, J., Rodriguez-Carvajal, J. and Rebours, B. (2005) Direct Localization of Atoms in Mixed-Occupancy Powders by Resonant Contrast Diffraction. Angew. Chem. Int. Ed., 44, 1725.

27 Wulf, R. (1990) Experimental Distinction of Elements with Similar Atomic Number Using Anomalous Dispersion ( $\delta$ synthesis): an Application of Synchrotron Radiation in Crystal structure Analysis. Acta Crystallogr., A46, 681.

28 Coppens, P., Lee, P., Gao, Y. and Sheu, H.S. (1991) Application to the Selective Atom Diffraction Method to the Cation Distribution in High $\mathrm{T}_{\mathrm{c}}$ Bismuth Cuprates. J. Phys. Chem. Solids, 52, 1267.

29 Palancher, H., Hodeau, J.L., Pichon, C., Bérar, J.F., Lynch, J. and Rebours, B. Manuscript in preparation.

30 see "Symposium on Applications of Particle Detectors in Medicine, Biology and Astrophysics II; Associated Workshop on Future Detectors for Synchrotron-Radiation and FELs; http://www.elettra.trieste.it/sites/samba/index.html

31 Bérar, J.F., Blanquart, L., Boudet, N., Breugnon, P., Caillot, B., Clémens, J.C., Delpierre, P., Mouget, C., Potheau, R. and Valin, I. (2002) A Pixel Detector with Large Dynamic Ronge for High Photon Counting Rates. J. Appl. Crystallogr., 35, 471.

32 Zhang, Y., Wilkinson, A.P., Nolas, G.S., Lee, P.L. and Hodges, J.P. (2003) Strategies for Solving NeighbouringElement Problems: a Case Study Using Resonant Powder
X-ray Diffraction and Pulsed Neutron Diffraction to Examine $\mathrm{Sr}_{8} \mathrm{Ga}_{16} \mathrm{Ge}_{30}$. J. Appl. Crystallogr., 36, 1182.

33 Warner, J.K., Wilkinson, A.P., Cheetham, A.K. and Cox, D.E. (1992) Comparative Study of Elemental Contrast by Resonant X-ray Diffraction and Neutron Powder Diffraction. J. Phys. Chem. Solids, 52, 1251.

34 Reimers, W., Hellner, E., Treutmann, W. and Heger, G. (1982) Magnetic Phase Diagram of the System $\mathrm{Mn}_{1-\mathrm{x}} \mathrm{Cr}_{\mathrm{x}} \mathrm{Sb}$ $(0 \leq \mathrm{x} \leq 1)$. J. Phys. C: Solid State Phys., 15, 3597.

35 Templeton, L.K. and Templeton, D.H. (1988) K-edge Anomalous Scattering in Zinc Tartrate Hydrate. J. Appl. Crystallogr., 21, 558.

36 Quintana, J.P., Butler, B.D. and Haeffner, D.R. (1991) Experimentally Determined Anomalous Scattering Factors for $\mathrm{Mn}, \mathrm{Fe}, \mathrm{Ni}, \mathrm{Cu}, \mathrm{Zn}$ and $\mathrm{Hg}$ Using the Kramers-Kronig Relation. J. Appl. Crystallogr., 24, 184.

37 Hill, R.J. and Madsen, I.C. (1984) The Effect of Profile Step Counting Time on the Determination of Crystal Structure Parameters by X-ray Rietveld Analysis. J. Appl. Crystallogr., 17, 297.

38 McCusker, L.B., Von Dreele, R.B., Cox, D.E., Louër, D. and Scardi, P. (1999) Rietveld Refinement Guidelines. J. Appl. Crystallogr., 32, 36.

39 Beauvais, C., Boutin, A. and Fuchs, A.H. (2004) A Numerical Evidence for Nonframework Cation Redistribution under Water Adsorption in Faujasite Zeolite. Chem. Phys. Chem., 5, 1791.

40 Buttefey, S., Boutin, A., Mellot-Draznicks, C. and Fuchs, H. (2001) A Simple Model for Predicting the $\mathrm{Na}^{+}$Distribution in Anhydrous NaY and NaX Zeolites. J. Phys. Chem., B105, 9569.

Final manuscript received in June 2005 